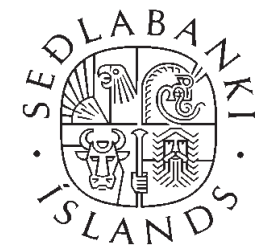

CENTRAL BANK OF ICELAND

WORKING PAPERS No. 28

The dynamic behavior of the real exchange rate in sticky price models

\author{
by \\ Jón Steinsson
}

November 2005

CENTRAL BANK OF ICELAND

Economics Department 
Central Bank of Iceland Working Papers are published by the Economics Department of the Central Bank of Iceland. The views expressed in them are those of their authors and not necessarily the views of the Central Bank of Iceland.

Also available on the Central Bank of Iceland World Wide Web site (http://www.sedlabanki.is)

All rights reserved. May be reproduced or translated provided the source is stated.

ISSN: 1028-9445 


\title{
The Dynamic Behavior of the Real Exchange Rate in Sticky Price Models
}

\author{
Jón Steinsson* \\ Harvard University
}

November 24, 2005

\begin{abstract}
I show that the empirical impulse response of the real exchange rate is hump-shaped. This fact can explain why a number of recent authors have been unable to match the persistence of the real exchange rate using sticky-price business cycle models driven by monetary shocks. The key failure of the models used in the recent literature is that they yield monotonic impulse responses for the real exchange rate. While it is extremely difficult for models that have this feature to match the empirical persistence of the real exchange rate, models that yield hump-shaped impulse responses for the real exchange rate can easily match the empirical persistence of the real exchange rate. I present a two-country sticky-price business cycle model that yields humpshaped responses for the real exchange rate in response to a number of different disturbances. This model can match the half-life of the real exchange rate as well as and the humped shape of its impulse response.
\end{abstract}

Keywords: Hump-Shaped Impulse Response, Half-life and Strategic Complementarity JEL Classification: F310, F410

${ }^{*}$ I would like to thank Kenneth Rogoff for invaluable advice and encouragement. I would also like to thank Marianne Baxter, Gita Gopinath, Anna Mikushava, Emi Nakamura, Thórarinn Pétursson, James Stock and seminar participants at Harvard for helpful comments and discussions. 


\section{Introduction}

One of the most prominent puzzles in international macroeconomics is the Purchasing Power Parity Puzzle. A simple theory based on goods market arbitrage and homogeneous tastes predicts that, if measured in a common currency, the price levels of different countries should be equal. A large empirical literature has found this theory to be wildly off the mark. Deviations from purchasing power parity are large, they are volatile and, furthermore, they are very persistent.

Rogoff (1996) characterized the central theoretical challenge posed by the empirical evidence about deviations from purchasing power parity (PPP) as: "How can one reconcile the enormous short-term volatility of real exchange rates with the extremely slow rate at which shocks appear to damp out?" While most explanations of the short term volatility of the real exchange rate point to models with nominal rigidities and financial shocks, consensus estimates of three to five year half-lives of PPP deviations are "seemingly far too long to be explained by nominal rigidities". On the other hand, while it is possible to rationalize slow adjustment if real shocks are predominate, "existing models based on real shocks cannot account for short-term exchange rate volatility."

Rogoff's argument that a half-life of PPP deviations of three to five years is seemingly far too long to be explained by nominal rigidities relies on the idea of a tight link between the length of time prices remain sticky and the persistence of the real effects caused by these nominal rigidities. Such a link need, however, not exist in models with staggered price setting (Taylor, 1980). In such models, the real effects of nominal rigidities can last longer than the length of time prices are sticky if the pricing decisions of firms are strategic complements.

In an influential paper, Chari, Kehoe and McGrattan (CKM, for short) set out to investigate formally whether a sticky price model with staggered price setting and driven by monetary shocks can match the empirical volatility and persistence of the real exchange rate seen in the data. ${ }^{1}$ Their conclusions are broadly in line with Rogoff's earlier claims: 1) Sticky price models can replicate the volatility of real exchange rates if the coefficient of relative risk aversion is assumed to be quite large (around five); and 2) Sticky price models can generate real exchange rates that are quite persistent, but less so than in the data. CKM refer to this second conclusion as the persistence anomaly. $^{2}$

\footnotetext{
${ }^{1} \mathrm{CKM}(2002)$.

${ }^{2} \mathrm{CKM}$ (2002) also draw attention to the fact that the class of models they consider implies that the real exchange rate should be highly correlated with home consumption relative to foreign consumption. They document that this is
} 
A number of papers have since sought to address this persistence anomaly in various ways. Bergin and Feenstra (2001) increase the degree of strategic complementarity in the model by assuming that agents have trans-log preferences and also by augmenting the model to allow for intermediate goods. They show that this increases the persistence of the real exchange rate somewhat but not enough to match its empirical persistence. Sondergaard (2004) also seeks to match the persistence of the real exchange rate by increasing the degree of strategic complementarity. The sources of strategic complementarity he employs are variable capital utilization and sticky wages. His conclusions largely parallel the conclusions of Bergin and Feenstra (2001). Benigno (2004) shows that specifying monetary policy as an interest rate rule with a smoothing term and allowing the home and foreign country to have differing degrees of price stickiness increases the persistence of the real exchange rate. However, he compares unfiltered data from his model with HP-filtered empirical data. His results are therefore not completely comparable with the papers discussed above, which compare HP-filtered model output with HP-filtered empirical data. ${ }^{3}$ Groen and Matsumoto (2003) show that asymmetric monetary policy across countries can increase the persistence of the real exchange rate and Bouakez (2005) argues that a model with a non-isoelastic demand structure can match the persistence of the real exchange rate. But like Benigno (2004) their results pertain to a comparison of unfiltered model data and filtered empirical data. None of the papers cited above are able to match the half-life of the real exchange rate or the autocorrelation of the HP-filtered real exchange rate. ${ }^{4}$

In this paper, I start by reexamining the empirical behavior of the U.S. real exchange rate since the break-up of the Bretton Woods system in 1973. The empirical literature on this topic has

not the case in the data. This anomaly has in recent years been referred to as the Backus-Smith puzzle (see, Backus and Smith, 1993). In this paper, I will not present a resolution of the Backus-Smith puzzle. Corsetti et al. (2004), Bodenstein (2005) and Choi (2005) present potential resolutions of this puzzle.

${ }^{3} \mathrm{CKM}$ (2002) measured the persistence of the real exchange rate as the first order autocorrelation of the HP-filtered real exchange rate. Their estimate of this statistic for the U.S. real exchange rate is 0.83 . They then compared this to the first order autocorrelation of the HP-filtered real exchange rate in their model which they find to be 0.62. Bergin and Feenstra (2001) and Sondergaard (2004) followed this same procedure. Benigno (2004), however, calculates the first order autocorrelation of the unfiltered real exchange rate from his model. He shows that this statistic is can be as high as 0.78 in his model for reasonable parameter values. Applying the HP-filter to a autocorrelated series lowers the autocorrelation of the series significantly. Benigno's results are therefor not entirely comparable to the results of CKM (2002), Bergin and Feenstra (2001) and Sondergaard (2004).

${ }^{4}$ The literature on the persistence puzzle for the real exchange rate largely parallels a larger literature about the ability of closed economy sticky price models with staggered price setting to match the persistence of business cycle fluctuations in output. Contributions to this literature include Ball and Romer (1990), Kimball (1995), Basu (1995), Jeanne (1998), CKM (2000), Bergin and Feenstra (2000), Woodford (2003), Christiano et al. (2005) and Neiss and Pappa (2005). 
focused almost exclusively on two issues: unit root tests and half-life estimation. The "consensus" view today is that real exchange rates are stationary but deviations from PPP have rather long half-lives (3 to 5 years). ${ }^{5}$ However, these two facts provide a incomplete picture of the dynamic behavior of the real exchange rate. Only if the real exchange rate is well described empirically by an $\operatorname{AR}(1)$ model does the half-life fully describe its dynamic behavior. In order to gain a more complete picture of the dynamics of the real exchange rate, I expand the set of statistics considered.

My main empirical result is that real exchange rates have hump-shaped impulse responses. More specifically, I estimate a univariate $\mathrm{AR}(\mathrm{p})$ time-series model for the real exchange rates and show that the estimated impulse reponse function (the moving average representations of the series) is hump-shaped. ${ }^{6}$ This is most clearly illustrated in figure 2 , which plots the impulse response of a trade weighted U.S. real exchange rate. The impulse response rises for several periods after the impulse. It then begins to fall. Only after 12 quarters does it fall below one (the size of the impulse). After that is falls quite rapidly; falling below $1 / 2$ in about 17 quarters and below $1 / 4$ in less than 22 quarters. My main measure of the real exchange rate is a trade weighted measure of the U.S. real exchange rate published by the Federal Reserve. For robustness, I also consider all the bilateral real exchange rates between Canada, Germany, Japan, Switzerland, the U.K and the U.S.. I estimate a hump-shaped impulse response for 13 of these 15 bilateral real exchange rates.

An implication of the fact that the impulse response of the real exchange rate is hump-shaped is that the half-life is a misleading measure of its persistence. The literature on the dynamics of the real exchange rate has tended to interpret the half-life as the rate of mean reversion of the real exchange rate. The fact that the impulse response of the real exchange rate is hump-shaped, however, implies that this rate of mean reversion is not constant. The rate of mean reversion is slow initially but becomes faster as the short term dynamics of the series die out. The half-life measures the rate of mean reversion in the short run. It therefore overestimates the persistence of the real exchange rate. I show that, while the half-life of the real exchange rate - the time it takes the real exchange rate to fall below $1 / 2$ after a unit impulse - is 4.3 years, the time it takes the real

\footnotetext{
${ }^{5}$ I put the word consensus in quotation marks because there is a lively ongoing debate about whether this consensus view is correct. See, e.g., Imbs et al. (2005), Chen and Engel (2005), Reidel and Szilagyi (2005), Michael et al. (1997), A. Taylor (2001) and M. Taylor et al. (2001).

${ }^{6}$ Cheung and Lai (2000) reach a similar conclusion for several U.S. bilateral exchange rates. Eichenbaum and Evans (1995) show that the response of the nominal exchange rate to an identified monetary policy shock is humpshaped. Huizinga (1987) finds evidence of positive serial correlation of changes in the U.S. real exchange rate at low lags. This suggestive evidence has, however, been largely ignored. I show that it has important consequences for the theoretical literature that seeks to match the persistence of the real exchange rate.
} 
exchange rate to half again - fall from $1 / 2$ to $1 / 4$ - is only 1.1 years. This latter number is a better measure of the rate of mean reversion of the real exchange rate after its short term dynamics have died out.

I emphasize the humped shape of the impulse response of the real exchange rate not only because it helps paint a more complete empirical picture of the dynamics of the real exchange rate, but also because it provides valuable guidance about what type of theoretical model will be able to match the persistence of the real exchange rate. Hump-shaped dynamics are a powerful source of endogenous persistence that has been entirely overlooked by the recent theoretical literature on real exchange rates. I show that a model that generates hump-shaped dynamics for the real exchange rate can quite easily match the persistence of the real exchange rate. I therefore conclude that the key problem with existing models of the real exchange is not an inability to generate persistence but rather the fact that they don't generate hump-shaped dynamics for the real exchange rate.

I present a two country sticky-price model with staggered price setting which is flexible enough to encompass a number of the models used in the recent literature on real exchange rate persistence. I show that in this model increasing the degree of strategic complementarity is not sufficient to generate the observed degree of persistence in the real exchange rate in response to a money supply shock. Furthermore, I show that in response to money supply shocks the model implies an exponentially decaying impulse response function for the real exchange rate. It therefore fails along two empirical dimensions.

I then show that the same model can easily match both the half-life of the real exchange rate and the humped shape of its impulse response function if the assumption that business cycles are due solely to money supply shocks is abandoned. I show how five different types of shocks - productivity shocks, labor supply shocks, government spending shocks, shocks to the world demand for home goods and cost-push shocks - all yield the same joint dynamics for consumption, inflation, interest rates and the real exchange rate in the model. These shocks imply a hump-shaped impulse response for the real exchange rate and can easily generate a half-life equal to the estimated half-life of the U.S. real exchange rate.

The paper proceeds as follows: Section 2 contains the empirical analysis about the real exchange rate. In section 3 , I present the model. In section 4, I present the theoretical results. Section 5 concludes. 


\section{Empirical Evidence}

The post-Bretton Woods empirical literature on real exchange rates has focused largely on two issues: unit root tests and half-life estimation. In the 1970's and early 1980's, researchers using post-Bretton Woods data were unable to find statistical support for even the minimal claim that the real exchange rate had a tendency to revert back to some long-term average value (see, e.g., Roll 1979; Adler and Lehmann, 1983; Meese and Rogoff, 1988). However, the informativeness of these early studies was limited by the small samples they employed and the low power of unit root tests against highly persistent but stationary alternatives.

Frankel $(1986,1990)$ addressed this problem by expanding the sample period to include data going back to the 19th century. Using annual data on the U.S. dollar/Pound exchange rate from 1869 to 1987, Frankel was able to reject the unit root hypothesis in favor of stationarity. He estimated the rate of mean reversion to be $16 \%$ per year, implying a half-life of 4.1 years. $^{7}$ As time has passed, evidence against the unit root hypothesis has become stronger and more emphasis has been given to half-life estimation. Rogoff (1996) surveyed the literature on half-life estimation and noted the remarkable consensus among studies up to that point that the half-life of the real exchange rate is between 3 and 5 year. Over the last 10 years, the statistical methods used to estimate halflives have improved markedly. Early estimates predominantly estimated AR(1) models by OLS. Recent studies - such as Murray and Papell (2002)-use median unbiased estimation methods to estimate an $\mathrm{AR}(\mathrm{p})$ model and calculate confidence intervals using bootstrap methods. ${ }^{8}$

While these advances are important, they still provide an incomplete picture of the dynamic behavior of the real exchange rate. Only if the real exchange rate is well described by an $\operatorname{AR}(1)$ model does the half-life fully describe its dynamic behavior. More generally, processes with quite different dynamic properties can generate equal half-lives. In order to be able to provide a more complete picture of the dynamics of the real exchange rate, it is essential to expand the set of statistics considered beyond the current focus on half-lives.

\footnotetext{
${ }^{7} \mathrm{~A}$ second strand of the literature has proposed to address the lack of power of the early unit root tests of the real exchange rate by jointly testing a unit root hypothesis for a number of countries. Researchers that have employed this methodology have had considerable success rejecting the unit root hypothesis (see, e.g., Abuaf and Jorion, 1990; Frankel and Rose, 1996). These studies have, by and large, find similar half-lives as the studies that use long time series for a single country.

${ }^{8}$ Other important advances include the estimation of aggregation bias (See, Imbs et al., 2005; Chen and Engel, 2005; Reidel and Szilagyi, 2005) and non-linearities (See, e.g., Michael et al., 1997; A. Taylor, 2001; M. Taylor et al., 2001).
} 
To this end, I report two sets of statistics. First, I report the impulse response function of the real exchange rate. Second, I report the "up-life", half-life and "quarter-life" of the real exchange rate. I follow the recent empirical literature on the real exchange rate in defining the half-life as the largest time $T$ such that $I R(T-1) \geq 0.5$ and $I R(T)<0.5$, where $I R(T)$ denotes the impulse response of the real exchange rate at time $T$. I define the up-life and the quarter-life analogously. The up-life is the largest time $T$ such that $I R(T-1) \geq 1$ and $I R(T)<1$. The quarter-life is the largest time $T$ such that $\operatorname{IR}(T-1) \geq 0.25$ and $\operatorname{IR}(T)<0.25$. Just as the half-life is meant to measure the time it takes for the impulse response to fall below half, the up-life is the time it take for the impulse response to fall below one and the quarter-life is the time it take for the impulse response to fall below a quarter.

The empirical specification I adopt is an $\mathrm{AR}(\mathrm{p})$ model with an intercept but no time trend. This model may be written in augmented Dickey-Fuller regression form as

$$
q_{t}=\mu+\alpha q_{t-1}+\sum_{j=1}^{p} \psi_{j} \Delta q_{t-j}+\epsilon_{t} .
$$

I calculate approximately median unbiased estimates of $\alpha$ and $\psi_{j}$ using the grid-bootstrap method described in Hansen (1999). This method is closely related to the method proposed by Andrews and Chen (1994). Point estimates for the impulse response, the half-life, up-life, quarter-life and other statistics are calculated from the point estimates for $\alpha$ and $\psi_{j}$. I then calculate conventional bootstrap confidence intervals for all these statistics.

I consider two datasets. First, I consider a trade weighted U.S. real exchange rate series against "major trading partners" published by the Federal Reserve Board. ${ }^{9}$ Second, I consider the bilateral real exchange rates of Canada, Germany, Japan, Switzerland, the U.K and the U.S.. I construct these real exchange rate series using data on nominal exchange rates and consumer price levels obtained from the International Financial Statistics database published by the IMF. All data series are sampled at a quarterly frequency from 1973:1-2002:4.

The first issue that arises is the choice of lag length. I considered a range of values for $p$ from 1 to 8. For values of $p$ smaller than 4 , the shape of the estimated impulse response function is quite sensitive to the chosen lag length. However, for values of $p$ between 4 and 8 the estimated impulse response is virtually identical. From this I conclude that a lag length of at least 4 is needed to flexibly estimate the impulse response. I choose to set $p=5$.

\footnotetext{
${ }^{9}$ See http://www.federalreserve.gov/releases/h10/summary/
} 
Results from the estimation of equation (1) for the trade weighted U.S. real exchange rate are presented in table 1 and figure 2. First, notice that the half-life estimate I obtain is consistent with the results of Murray and Papell (2002) and the earlier literature surveyed by Rogoff (1996). The point estimate is 4.3 years and therefore within the "consensus range" of 3 to 5 years. Also, consistent with Murray and Papell (2002), the 95\% confidence interval for the half-life is very wide. Even 30 years after the breakdown of Bretton Woods, it is not possible to estimate the half-life of the real exchange rate with much precision.

A second salient feature of the estimated dynamics of the real exchange rate is the pronounced hump in the impulse response function plotted in figure 2. Rather than dying out exponentially, the impulse response keeps rising for a number of periods before it starts dying out. As a consequence of this, the impulse response function doesn't fall below 1 (the size of the impulse) until 12 quarters after the impulse. This feature of the data has received little attention in the recent literature. ${ }^{10}$

As with persistence, it is useful to define scalar measures of the degree of "hump" in the impulse response function. When defining these measures, I consider an impulse response that dies out at a constant exponential rate as the benchmark "no hump" case. Notice that such a process will have an up-life of zero since the impulse response monotonically decreases after the initial impulse and therefore never rises above one. A non-zero up-life can, therefore, be viewed as evidence that the process has a hump-shaped impulse response. This fact suggests that it is sensible to measure the degree of hump in the impulse response is as the ratio of the up-life to the half-life (UL/HL). The $\mathrm{UL} / \mathrm{HL}$ is a measure between 0 and 1 . It measures the fraction of time before the impulse response falls below 1 out of the total time before it falls below $1 / 2$.

Another feature of an impulse response that dies out at a constant exponential rate is that it takes the process the same amount of time to fall from $1 / 2$ to $1 / 4$ as it take to fall from 1 to $1 / 2$. In other words, the half-life is equal to the quarter-life minus the half-life (HL = QL - HL). On the other hand, for a process that has a hump-shaped impulse response the half-life is larger than the quarter-life minus the half-life (HL > QL - HL). Or written slightly differently $2 \mathrm{HL}-\mathrm{QL}>0$. These facts suggest that $2 \mathrm{HL}$ - QL, or equivalently the difference between HL and QL - HL, can be viewed as a measure of the degree of humped in the impulse response.

In table 1, I report estimates of the statistics discussed above. The UL of the trade weighted

\footnotetext{
${ }^{10}$ A notable exception to this is Cheung and Lai (2000).
} 
U.S. real exchange rate is 3.1 years. This implies that the UL/HL is 0.71 . So, $71 \%$ of the time that it takes the real exchange rate to fall below $1 / 2$ it is actually above one.

The UL/HL shows that it takes a number of quarters for the real exchange rate to start reverting toward its mean after an impulse. A comparison of the quarter-life and the half-life shows that once it starts reverting towards its mean it does so quite quickly. I estimate the quarter-life of the U.S. real exchange rate to be only 5.4 years. This implies that the QL - HL - the time it takes the real exchange rate to fall from $1 / 2$ to $1 / 4$ - is only 1.1 years. The rate of mean reversion of the real exchange rate is therefore quite rapid after the initial short term dynamics have played out.

The literature on the dynamics of the real exchange rate has tended to interpret the half-life as its rate of mean reversion. The results discussed above show that this is misleading. The rate of mean reversion of the real exchange rate is far from being constant. The half-life measures the rate of mean reversion in the short run. It is therefore heavily affected by the short term dynamics of the real exchange rate. The QL - HL, however, measures the rate of mean reversion further out, when the short term dynamics have mostly died out. My results show that the rate of mean reversion of the real exchange rate is very slow initially but becomes substantially faster after the short term dynamics die out.

In tables 2-3, I present results for 15 bilateral real exchange rates. In panel A of table 2, I report the UL/HL for each case. In 13 of the 15 cases, the UL/HL is positive. In the case of the U.S./Canadian real exchange rate I estimate a unit root. For this case UL/HL is not defined. Only in the case of the German/Swiss real exchange rate is UL/HL $=0$. The median UL/HL is 0.40. In panel B of table 2, I report the HL and QL - HL for each of the 15 bilateral real exchange rates. Again, in 13 of 15 cases HL > QL - HL. The median HL is 3.25 while the median QL - HL is 2.15.

Table 3 presents three sets of hypothesis tests. In panel A, I report P-values for the hypothesis $\mathrm{UL} / \mathrm{HL}=0$. This panel shows that, unlike in the case of the trade weighted U.S. real exchange rate, the statistical significance of the hypothesis that $\mathrm{UL} / \mathrm{HL}>0$ is rather weak for these bilateral real exchange rates. The median $\mathrm{P}$-value is 0.23 . In panel $\mathrm{B}, \mathrm{I}$ report $\mathrm{P}$-values for a test statistic testing $\mathrm{HL}=\mathrm{QL}-\mathrm{HL}$. Again these tests are not rejected with overwhelming strength. In this case the median P-value is 0.10 . For comparison, I report a test statistic testing the unit root hypothesis $\alpha=1$. The significance level at which this hypothesis can be rejected also varies quite a bit. The median P-value is 0.08 . The statistical support for the hypothesis that the impulse 
response of bilateral real exchange rates is hump-shaped therefore seems to be slightly weaker than the significance of the hypothesis that these bilateral real exchange rates are stationary.

To sum up, I find strong statistical evidence that the trade weighted U.S. real exchange rate has a hump-shaped impulse response. Point estimates suggest that the bilateral real exchange rates of Canada, Germany, Japan, Switzerland, the U.K. and the U.S. are also hump-shaped. The size and statistical significance of the hump in non-U.S. real exchange rates is weaker than for the U.S. real exchange rates. Below I show that the models used in the theoretical literature on real exchange rate dynamics do not capture the humped dynamics of the real exchange rate. I furthermore show that models that do capture the hump are also able to fit the long half-lives of real exchange rates better than existing models.

\section{The Model}

The model I employ to understand the stylized facts about the dynamics of the real exchange rate discussed above is a two country model in the tradition of Obstfeld and Rogoff (1995). It incorporates a number of features that have been developed in the subsequent literature such as staggered price setting, local currency pricing, home biased preferences and heterogeneous factor markets. The core of the model consists of five equations. Aggregate consumption in each country evolves according to consumption Euler equations:

$$
\begin{gathered}
c_{t}=E_{t} c_{t+1}-\sigma\left(i_{t}-E_{t} \pi_{t+1}\right), \\
c_{t}^{*}=E_{t} c_{t+1}^{*}-\sigma\left(i_{t}^{*}-E_{t} \pi_{t+1}^{*}\right) .
\end{gathered}
$$

The dynamics of inflation in each country are governed by New Keynesian Phillips curves:

$$
\begin{aligned}
& \pi_{t}=\beta E_{t} \pi_{t+1}+\kappa \zeta\left[\phi_{H} c_{t}^{M}+\phi_{F} c_{t}^{M *}\right]+\kappa \gamma_{q} q_{t}-\eta_{t}, \\
& \pi_{t}^{*}=\beta E_{t} \pi_{t+1}^{*}+\kappa \zeta\left[\phi_{F} c_{t}^{M}+\phi_{H} c_{t}^{M *}\right]-\kappa \gamma_{q} q_{t}-\eta_{t}^{*},
\end{aligned}
$$

And optimal international risk-sharing yields a "Backus-Smith" condition:

$$
c_{t}-c_{t}^{*}=\sigma q_{t}
$$

Here $c_{t}$ denotes home consumption, $\pi_{t}$ denotes home CPI inflation, $i_{t}$ denotes the home short-term nominal interest rate, $q_{t}$ denotes the real exchange rate and $\eta_{t}$ is a composite of five different types 
of shocks: productivity shocks, labor supply shocks, government spending shocks, shocks to the world demand for home goods and cost-push shocks. All variables denote percentage deviations from a steady state with balanced trade. Foreign variables are denotes with asterisks. Superscript $M$ and $M *$ denote the following weighted averages: $c_{t}^{M}=\phi_{H} c_{t}+\phi_{F} c_{t}^{*}$ and $c_{t}^{M *}=\phi_{F} c_{t}+\phi_{H} c_{t}^{*}$, where $\phi_{H}$ is the steady state fraction of total spending allocated to domestic goods and $\phi_{F}$ is the corresponding fraction allocated to imports.

A fully microfounded model that yields these equations up to a log-linear approximation is presented in detail in appendix A. This model features a continuum of household types each of which consumes and supplies labor. Each type of household consumes a basket of all goods produced in the world economy but supplies a differentiated labor input. Household preference are biased in favor of home goods. There is a continuum of monopolistically competitive firms. Each firm demands labor and produces a differentiated good. Goods prices are sticky. The opportunity to revise prices arrives randomly as in Calvo (1983). Firms are able to price to market and their prices are sticky in the local currency. Households have access to complete financial markets. The government in each country finances spending though lump-sum taxation of households.

In order to close the model, one must specify a monetary policy for each country. Following CKM (2002), I assume that monetary policy may described by the following four equations:

$$
\begin{gathered}
\Delta m_{t}-\pi_{t}=\psi_{c} \Delta c_{t}-\psi_{i} \Delta i_{t}, \\
\Delta m_{t}^{*}-\pi_{t}^{*}=\psi_{c} \Delta c_{t}^{*}-\psi_{i} \Delta i_{t}^{*} ; \\
\Delta m_{t}=\rho_{m} \Delta m_{t-1}+\nu_{t}, \\
\Delta m_{t}^{*}=\rho_{m} \Delta m_{t-1}^{*}+\nu_{t}^{*}
\end{gathered}
$$

The traditional way to motivate these equations is as a pair of LM equations and money growth rules. Under this interpretation $m_{t}$ denotes the home money supply. However, one can also think of equations (7) and (8) as interest rate policy rules and $\Delta m_{t}$ and $\Delta m_{t}^{*}$ as a persistent shock to these policy rules. I assume that $\nu_{t}$ and $\nu_{t}^{*}$ are i.i.d. mean zero random variables.

Finally, I assume that

$$
\begin{aligned}
& \eta_{t}=\rho_{\eta} \eta_{t-1}+\epsilon_{t}, \\
& \eta_{t}^{*}=\rho_{\eta} \eta_{t-1}^{*}+\epsilon_{t}^{*},
\end{aligned}
$$


where $\epsilon_{t}$ and $\epsilon_{t}^{*}$ are i.i.d. mean zero random variables. Given initial conditions, equations (2)-(12) then constitute a fully specified general equilibrium model of the world economy.

\section{Theoretical Results}

The theoretical question that I address in this section is whether the model described above can replicate the stylized facts about the dynamics of the real exchange rate discussed in section 2 . The model consists of a set of linear equations with expectations terms. This type of model may be solved using standard methods based on the work of Blanchard and Kahn (1980). ${ }^{11}$ To aid comparison with earlier work, I use values for the parameters of the model that correspond as closely as possible to the parameters used in CKM (2002). I list the values of the parameters in table 5 .

My main theoretical results are presented in table 4. The first row of this table repeats, for convenience, the stylized empirical facts about the real exchange rate established in section 2 . In The second row, I report results for the model presented in section 3 under the assumption that factor markets in each country are homogeneous and business cycles are due only to money supply shocks. ${ }^{12}$ This specification of the model is designed to correspond to the benchmark model in CKM (2002). The results in table 4 confirm that it does. The real exchange rate is much less persistent than in the data. This is true whether one measures persistence by the half-life of the impulse response -0.58 years versus 4.33 years in the data - or by the autocorrelation of the series after it as been HP-filtered- 0.54 versus 0.82 in the data.

A large number of papers have in recent years argued that the reason why simple, largely frictionless models, such as the model used by CKM (2002), are unable to match the persistence of key business cycle variables is that they seriously underestimate the degree of strategic complementarity (a.k.a. real rigidities) in the economy. ${ }^{13}$ Bergin and Feenstra (2001) and Sondergaard (2004), apply these theoretical ideas to the problem of generating persistence in the real exchange rate.

\footnotetext{
${ }^{11}$ I use Chris Sims' gensys.m matlab program to solve the model. See Sims (2001) for a description of the algorithm that this program implements. The program is available at http://sims.princeton.edu/yftp/gensys/.

${ }^{12}$ The structure of the factor markets - whether they are homogeneous or heterogeneous - affects the model through the parameter $\zeta$. This is discussed in more detail below and in appendix A. The assumption that business cycles are due only to money supply shocks simply means that the variance of shocks to the Phillips curves was set to zero in this simulation.

${ }^{13}$ See Taylor (1999), Bergin and Feenstra (2000) and Woodford (2003, section 3.1) and references in these papers.
} 
They find that increasing the degree of strategic complementarity increases the persistence of the real exchange rate somewhat. But they are unable to match the persistence seen in the data.

In the model presented above, the parameter $\zeta$ is a measure of the average degree of strategic complementarity of firm pricing decisions. ${ }^{14}$ If $\zeta<1$, the pricing decisions of firms are strategic complements on average. If, however, $\zeta>1$, firm pricing decisions are strategic substitutes on average. Loosely speaking, strategic complementarity implies that the price level will react less to nominal disturbances than the fraction of firms able to change their prices might suggest and the real effects of nominal disturbances will persist longer than the length of time until most prices have changed. Strategic substitutability implies the opposite. ${ }^{15}$

Under the assumption of homogeneous factor markets $\zeta=\omega+\sigma^{-1}=8$. This specification of the model therefore implies a substantial degree of strategic substitutability. The recent literature has identified many sets of plausible assumptions that imply much more strategic complementarity. These include non-isoelastic demand, intermediate inputs, variable capital utilization, sticky wages and heterogeneous factor markets. ${ }^{16}$

In the third row of table 4, I report results for the model with heterogeneous factor markets. All other assumptions are the same as before. Under this assumption about the factor markets, $\zeta=\left(\omega+\sigma^{-1}\right) /(1+\omega \theta)=0.26$, implying a large degree of strategic complementarity. In this respect this specification is meant to match the model used in Bergin and Feenstra (2001) and Sondergaard (2004). The results for this model confirm that increasing the degree of strategic complementarity in the model increases the persistence of the real exchange rate. However, the persistence of the real exchange rate is still substantially less persistent than in the data. These results therefore complement the results of Bergin and Feenstra (2001) and Sondergaard (2004).

In the fourth row in table 4, I report results for a calibration of the model that I have dubbed "extreme". It is extreme in that I have set $\zeta=0.01$ and the $\rho=0.95$. As the name suggests, this is not meant to be a realistic calibration. Rather, I have included it to illustrate that even given very extreme assumptions about the degree of strategic complementarity and the persistence of money

\footnotetext{
${ }^{14}$ I show this formally in appendix B.

${ }^{15}$ See Woodford (2003, section 3.1) for a more detailed explanation of the role of strategic complementarity in business cycle models of this type.

${ }^{16}$ Kimball (1995) and Bergin and Feenstra (2000, 2001) consider non-isoelastic demand. Basu (1995) and Bergin and Feenstra (2000, 2001)considers intermediate inputs. Christiano et al. (2005) and Neiss and Pappa (2005) consider variable capital utilization. Jeanne (1998), Erceg et al. (2000), Woodford (2003, section 3.4) and Christiano et al. (2005) consider sticky wages. Kimball (1995) and Woodford (2003, section 3.1) consider heterogeneous factor markets.
} 
growth shocks the model does not fit the empirical features of the real exchange rate. In this case, the half-life of the real exchange rate is only 1.41 and the autocorrelation of the HP-filtered real exchange rate is only 0.65 .

Another striking shortcoming of the three specifications of the model discussed above is the fact that they totally fail to capture the humped shape of the impulse response the real exchange rate. For all three of these specifications, the median unbiased estimate of UL/HL is 0.00 and the estimate of QL - HL and HL are almost identical. Figure 3 plots the impulse response of the real exchange rate to a home money supply shock in the heterogeneous factor markets model. The impulse response dies out exponentially like an $\mathrm{AR}(1)$ processes.

Analysis of these first three specifications therefore yield two main results. First, increasing the degree of strategic complementarity in the model seems to be insufficient to match the empirical persistence the real exchange rate. Second, the benchmark sticky price model driven by money supply shocks fails to match the humped shape of the impulse response of the real exchange rate in the data.

Next consider the behavior of the model in response to Phillips curve shocks. In appendix A, I show that at least five different types of disturbances appear in the model as shocks to the Phillips curve. These are productivity shocks, labor supply shocks, government spending shocks, shocks to the world demand for home produced goods and cost-push shocks. The fact that all these different disturbances enter the model in the same way - as shocks to the Phillips curve - implies that they all have the same implications regarding the dynamics of consumption, inflation, interest rates and the real exchange rate. For the purpose of analyzing the dynamics of the real exchange rate I therefore need not make any assumptions about the relative importance of these five types of disturbances. ${ }^{17}$

I report results for the model with heterogeneous factor markets in which business cycles are driven by Phillips curve shocks in the fifth row of table 4 . The dynamics of the real exchange rate

\footnotetext{
${ }^{17}$ It is important to note that, while the five shocks that I lump together as Phillips curve shocks imply the same dynamic behavior for consumption, inflation, the interest rate and the real exchange rate, they don't all imply identical behavior for other variables such as output. For example, a positive productivity shock and a negative government spending shock both imply that inflation will fall and consumption will rise but they have different implications for output. Output will rise in response to a positive productivity shock but fall in response to a negative government spending shocks. By writing the model the way I have, I have been able to solve for the dynamics of the real exchange rate without making any reference to the dynamics of output. The impulse response of the real exchange rate in response to a Phillips curve shock is therefore consistent with a wide range dynamics for output (and other variables) depending on the relative importance of the five shocks that make up the Phillips curves shock in my model.
} 
differ in two ways from what they are when business cycles are driven by money supply shocks. First, in this case the model is able to match the persistence of the real exchange rate in the data quite well. The half-life of the real exchange rate is 3.81 compared with 4.33 in the data and the autocorrelation of the HP-filtered real exchange rate is 0.84 compared with 0.82 in the data.

Second, the model also generates a hump-shaped response of the real exchange rate to Phillips curve shocks. Figure 4 plots the response of the real exchange rate to a home Phillips curve shock. The response of the real exchange rate to a money supply shock is plotted as well for comparison. Clearly the qualitative feature of the impulse response are very different and much more in line with the empirical impulse response in figure 2.

While the hump in the response of the real exchange rate to a Phillips curve shock is substantial, it is not quite as pronounced as in the data on the trade weighted U.S. real exchange rate. The UL/HL of the real exchange rate when business cycles are driven by Phillips curve shocks is 0.36 . The corresponding value for the trade weighted real exchange rate is 0.71 . The QL - HL in the model is 2.55 compared with 1.09 in the data. However, as I noted in section 2, the estimated hump for the trade weighted U.S. real exchange rate is more pronounced than the estimated hump in other real exchange rate measures. The results for the model actually match the median values of the HL, UL/HL and QL - HL in table 2 quite well.

In order to understand why Phillips curve shocks yield a hump-shaped impulse response for the real exchange rate while money supply shocks do not, it is helpful to take a closer look at the structural equations of the model. If the home consumption Euler equation-equation (2) - is "solved forward", it yields

$$
c_{t}=-\sigma E_{t} \sum_{j=0}^{\infty}\left(i_{t+j}-E_{t+j} \pi_{t+1+j}\right) .
$$

According to the Backus-Smith condition, $q_{t}=\sigma^{-1}\left(c_{t}-c_{t}^{*}\right)$. Due to the large amount of homebias that I have assumed (in order to match the empirical ratio of imports to consumption), home shocks have very muted effects on foreign variables and vice versa. ${ }^{18}$ This implies that the impulse response of the real exchange rate is close to being a scaled version of the impulse response of home consumption when the impulse in question is a shock to the home country. Shocks that imply

\footnotetext{
${ }^{18} \mathrm{My}$ results are not very sensitive to the high degree of home-bias I assume. Decreasing the degree of home-bias weakens my results somewhat-i.e., makes the real exchange rate less volatile and less hump-shaped. But even if I calibrate the home-bias to match the import share in consumption for a small country such as Sweden my results don't change significantly.
} 
hump-shaped impulse responses for consumption will therefore also imply hump-shaped impulse responses for the real exchange rate. ${ }^{19}$

If consumption is to be hump-shaped, the sum on the right hand side of equation (13) must be hump-shaped. Considering for concreteness a shock that raises home consumption, this means that while the sum on the right hand side of equation (13) must become negative on impact the first few element of the sum must be positive. This pattern implies that the sum will become more negative for a few periods as the positive terms drop out of the sum. In other words, for consumption to be hump-shaped, the impulse response of the real interest rate must be shaped roughly as in figure 5 .

The crucial difference between money supply shocks and Phillips curve shocks is that money supply shocks lead inflation and consumption to move in the same direction on impact while Phillips curve shocks lead these variables to move in opposite directions on impact. This is illustrated in figures 6 and 7 . Figure 6 plots the response of home consumption and home inflation to a home money supply shock. A positive money supply shock increases consumption. The boom in consumption, in turn, causes inflation to rise. As the shock dissipates, consumption and inflation return to their steady state values monotonically.

Figure 7 plots the response of home consumption and home inflation to a home Phillips curve shock. A positive Phillips curve shock, in contrast, increases consumption and decreases inflation on impact. As the shock dissipates inflation rises above trend due to the boom in consumption. Both series then return to steady state. The Phillips curve shock therefore causes a non-monotonic impulse response for inflation which yields a similar non-monotonic impulse response for the real interest rate if the response of the nominal interest rate is not too strong. It is this non-monotonic impulse response of the real interest rate that causes consumption and the real exchange rate to be hump-shaped, as I described above.

Another way to understand the difference between Phillips curves shocks and other shocks is as the difference between movements along the Phillips curve and movements due to shifts in the Phillips curve. If the home Phillips curve - equation (4) - is solved forward, it yields

$$
\pi_{t}=\kappa E_{t} \sum_{j=0}^{\infty} \beta^{j}\left[\zeta \phi_{H} c_{t+j}^{M}+\zeta \phi_{F} c_{t+j}^{M *}+\gamma_{q} \sigma^{-1} c_{t}^{R}\right]+E_{t} \sum_{j=0}^{\infty} \beta^{j} \eta_{t+j}
$$

\footnotetext{
${ }^{19}$ In a model in which utility is not time separable or not separable between consumption and leisure, the BackusSmith condition would become $q_{t}=\sigma^{-1}\left(\lambda_{t}-\lambda_{t}^{*}\right)$, where $\lambda_{t}=\partial U / \partial C_{t}$. This is why adding habit formation to the model presented in appendix A does not yield a hump-shaped impulse response for the real exchange rate. Such a model yields a hump-shaped path for consumption but does not yield a hump-shaped path for marginal utility and therefore not a hump-shaped path for the real exchange rate.
} 
where $c_{t}^{R}=c_{t}-c_{t}^{*}$. This equation shows that movements along the Phillips curve yield a positive relationship between inflation and the expectation of a distributed lead of consumption. Fluctuations due to other shocks than Phillips curve shocks therefore tend to lead consumption and inflation to move together. A shock to the Phillips curve disrupts this relationship and leads consumption and inflation to move in opposite directions on impact. As the shock dissipates, however, what is left is the effect on consumption (which dissipates slower than the shock due to the strategic complementarities). Inflation therefore reverses directions and its deviation from steady state switches sign.

To summarize, sticky price models driven solely by money supply shocks are unable to match the humped shape and the persistence of the real exchange rate even when a large degree is strategic complementarity is assumes and the shock is assumed to be highly persistent. In contrast, these same models, when driven by Phillips curves shocks, can match both the persistence of the real exchange rate and the humped shape of its impulse response.

\section{Conclusions}

A number of authors have recently attempted to build models that matched the persistence of the real exchange rate. These attempts have been largely unsuccessful. In this paper, I show that this lack of success is due to the fact that the literature has not taken account of the fact that the empirical impulse response of the real exchange rate is hump-shaped.

I begin by documenting this fact empirically. I show that the impulse response of the U.S. real exchange rate rises for several periods aften an impulse before beginning to fall. The impulse response falls below one (the size of the impulse) after 12 quarters. After this the rate of mean reversion is quite rapid. An implication of this is that the half-life of the real exchange rate overestimates its persistence. While the half-life is 4.3 years the quarter-life minus the half-lifethe time it takes to fall from $1 / 2$ to $1 / 4$ - is only 1.1 years.

I then present a two country sticky price model with staggered price setting which is flexible enough to encompass most of the models used in the recent literature on real exchange rate persistence. I show that in this model increasing the degree of strategic complementarity is not sufficient to generate the observed degree of persistence in the real exchange rate in response to a money supply shock. This is due to the fact that in response to money supply shocks these models imply 
an exponentially decaying impulse response function for the real exchange rate.

I show that the same model yields a hump-shaped impulse response of the real exchange rate in response to productivity shocks, labor supply shocks, government spending shocks, shocks to the world demand for home goods and cost-push shocks. Assuming that business cycles are due to a combination of these five shocks, it is relatively easy to match the half-life of the real exchange rate as well as the humped shape of its impulse reponse. 


\section{A A Detailed Derivation of the Model}

\section{A.1 Household Behavior and Market Structure}

The world consists of two countries. In each country there is a continuum of household types indexed by $x$. The home country households have indexes on the interval $N_{H}=[0,1]$. The foreign country households have indexes on the interval $N_{F}=(1,2]$. Home households of type $x$ seek to maximize a discounted sum of utilities represented by

$$
E_{0}\left\{\sum_{t=0}^{\infty} \beta^{t}\left[u\left(C_{t}\right)-v\left(L_{t}(x), \xi_{t}\right)\right]\right\}
$$

where $\beta$ is a discount factor, $\xi_{t}$ is a country specific vector of shocks to the household's preferences, $C_{t}$ denotes household consumption of a composite consumption good, $L_{t}(x)$ denotes the households' supply of differentiated labor input $x$. The function $u\left(C_{t}\right)$ is increasing and concave while $v\left(L_{t}(x), \xi_{t}\right)$ is increasing and convex in $L_{t}(x)$. There is an equal (large) number of households of each type $x$.

The consumption index in equation (14) is

$$
C_{t}=\left[\phi_{H, t}^{\frac{1}{\eta}} C_{H, t}^{\frac{\eta-1}{\eta}}+\phi_{F, t}^{\frac{1}{\eta}} C_{F, t}^{\frac{\eta-1}{\eta}}\right]^{\frac{\eta}{\eta-1}}
$$

where $\eta>0$ denotes the elasticity of substitution between home and foreign goods and the $\phi_{j, t}$ 's are a preference parameter that determines households' relative preference for home versus foreign goods. If $\phi_{H, t}>\phi_{F, t}$, households preferences are biased toward home produced goods. It is analytically convenient to normalize $\phi_{H, t}+\phi_{F, t}=1$. I allow the home bias in preferences to vary exogenously over time and refer to such variation as expenditure shocks. I assume for simplicity that households in both countries have the same degree of steady state home bias, i.e., $\phi_{H}^{*}=\phi_{F}$.

The subindices, $C_{j, t}$, are in turn CES indices of the differentiated goods produced in the two countries. These indices are given by

$$
C_{H, t}=\left[\int_{N_{H}} c_{t}(z)^{\frac{\theta_{t}-1}{\theta_{t}}} d z\right]^{\frac{\theta_{t}}{\theta_{t}-1}}, \text { and } C_{F, t}=\left[\int_{N_{F}} c_{t}(z)^{\frac{\theta_{t}^{*}-1}{\theta_{t}^{*}}} d z\right]^{\frac{\theta_{t}^{*}}{\theta_{t}^{*}-1}} .
$$

Here the differentiated goods are indexed by $z$. The consumption by the representative household in the home country of good $z$ in period $t$ is denoted by $c_{t}(z)$ and $\theta_{t}>1$ and $\theta_{t}^{*}>1$ denote the elasticity of substitution at time $t$ between the differentiated goods produced in the home country and foreign country, respectively. I assume that $\theta_{t}$ and $\theta_{t}^{*}$ vary exogenously. These variations may 
be interpreted as variation in the monopoly power of firms in the two countries. In the recent literature on monetary policy, these shocks have been referred to as "cost-push" shocks.

All goods produced in the economy are non-durable consumption goods purchased and consumed immediately by households. Investment and capital accumulation play no role in the model. To the extent that capital is used in production, each firm in the economy is endowed with a fixed amount of non-depreciating capital. Labor is immobile and there are a fixed number of firms operating in each country.

Each country has a government. These governments operate fiat currency systems denominated in "home currency" and "foreign currency", respectively. There are independent central banks that conduct monetary policy in each country by controlling the short term nominal interest rate in the domestic currency. ${ }^{20}$ The governments finance spending by lump sum taxes.

Households face a decision in each period about how much to consume of each of the differentiated goods produced in the world. The representative household seeks to maximize the value of the composite consumption good, $C_{t}$, that it can purchase given its income and given the prices it faces. Prices in the home country are denominated in home currency and are denoted by $p_{t}(z)$. Prices in the foreign country are denominated in foreign currency and are denoted by $p_{t}^{*}(z)$. The demand for home produced good $z$ that results from this optimization by the home and foreign households is

$$
c_{t}(z)=C_{H, t}\left(\frac{p_{t}(z)}{P_{H, t}}\right)^{-\theta_{t}} \text { and } \quad c_{t}^{*}(z)=C_{H, t}^{*}\left(\frac{p_{t}^{*}(z)}{P_{H, t}^{*}}\right)^{-\theta_{t}}
$$

where

$$
C_{H, t}=\phi_{H, t} C_{t}\left(\frac{P_{H, t}}{P_{t}}\right)^{-\eta} \text { and } C_{H, t}^{*}=\phi_{H, t}^{*} C_{t}^{*}\left(\frac{P_{H, t}^{*}}{P_{t}^{*}}\right)^{-\eta}
$$

Demand for foreign produced goods is given by analogous expressions. In these equations $P_{H, t}$, $P_{H, t}^{*}, P_{t}$ and $P_{t}^{*}$ are price indexes given by

$$
\begin{gathered}
P_{H, t}=\left[\int_{N_{H}} p_{t}(z)^{1-\theta_{t}} d z\right]^{\frac{1}{1-\theta_{t}}} \quad, \quad P_{H, t}^{*}=\left[\int_{N_{H}} p_{t}^{*}(z)^{1-\theta_{t}} d z\right]^{\frac{1}{1-\theta_{t}}}, \\
P_{t}=\left[\phi_{H, t} P_{H, t}^{1-\eta}+\phi_{F, t} P_{F, t}^{1-\eta}\right]^{\frac{1}{1-\eta}} \text { and } \quad P_{t}^{*}=\left[\phi_{H, t}^{*} P_{H, t}^{* 1-\eta}+\phi_{F, t}^{*} P_{F, t}^{* 1-\eta}\right]^{\frac{1}{1-\eta}} .
\end{gathered}
$$

$P_{t}$ and $P_{t}^{*}$ will be referred to as the home and foreign country price levels, respectively. For simplicity, I assume that the demand of the home and foreign governments - denoted by $g_{t}(z)$, $g_{t}^{*}(z), G_{j, t}, G_{j, t}^{*}, G_{t}$ and $G_{t}^{*}$-is given by analogous equations to equations (17) and (18).

\footnotetext{
${ }^{20}$ The monetary policy represented by equations (7)-(10) may be viewed as interest rate rules.
} 
Agents in both countries have access to complete financial markets. There are no impediments to international trade in financial securities. Home households of type $x$ face a flow budget constraint given by

$$
P_{t} C_{t}+E_{t}\left[M_{t, t+1} B_{t+1}(x)\right] \leq B_{t}(x)+W_{t}(x) L_{t}(x)+\int_{0}^{1} \Phi_{t}(z) d z-T_{t}
$$

where $B_{t+1}(x)$ is a random variable that denotes the state contingent payoff of the portfolio of financial securities held by households of type $x$ at the beginning of period $t+1, M_{t, t+1}$ is the stochastic discount factor that prices these payoffs in period $t, W_{t}(x)$ denotes the wage rate received by home households of type $x$ in period $t, \Phi_{t}(z)$ is the profit of firm $z$ in period $t$ and $T_{t}$ denotes lump sum taxes. ${ }^{21}$

A necessary condition for equilibrium in this model is that there exist no arbitrage opportunities. It follows from the absence of arbitrage opportunities that all portfolios of financial securities that pay off in period $t+1$ may be priced in period $t$ using a unique stochastic discount factor, $M_{t, t+1}$, as in equation (21). In order to rule out "Ponzi schemes," households' portfolios of financial wealth must always be large enough that future income suffices to avert default.

Home households choose $C_{t}, L_{t}(x)$ and $B_{t}(x)$ in order to maximize expression (14) subject to equation (21). An optimal plan must satisfy

$$
\begin{gathered}
u_{c}\left(C_{t}\right)=P_{t} \Lambda_{t}(x), \\
M_{t, T} \Lambda_{t}(x)=\beta^{T-t} \Lambda_{T}(x), \\
v_{l}\left(L_{t}(x), \xi_{t}\right)=W_{t}(x) \Lambda_{t}(x),
\end{gathered}
$$

where $\Lambda_{t}(x)$ denotes the marginal utility of nominal income of households of type $x$ at time $t$, that is, the Lagrange multiplier of the constrained optimization and subscripts on the functions $u$ and $v$ denote partial derivatives. These three equations should hold for all periods $t$ and all subsequent periods $T$.

The optimal plan must also satisfy the trasversality condition

$$
\lim _{j \rightarrow \infty} \beta^{j} E_{t}\left[u_{c}\left(C_{t+j}\right) \frac{B_{t+j}(x)}{P_{t+j}}\right] \leq 0
$$

\footnotetext{
${ }^{21}$ In equation (21) financial assets are denominated in the home currency and $M_{t, t+1}$ denotes the home currency nominal stochastic discount factor. It is important to note that the financial assets in equation (21) cannot generally be denominated in "goods". If goods are not freely traded internationally and don't have the same exchange rate adjusted price in the two countries, as will be assumed below, the same good in different countries must be viewed as two different goods. Financial assets can in this case be denominated in "goods for delivery in home country" or "goods for delivery in foreign country" but not "goods".
} 
for all $t$. It may be shown that a sufficient condition for equation (25) to hold is that $u_{c}\left(C_{t}\right) C_{t}$ be bounded. This is a rather standard assumption (see, e.g., Farmer, 1999).

Foreign households solve an analogous problem. Their optimal plan must satisfy

$$
\begin{aligned}
u_{c}\left(C_{t}^{*}\right) & =P_{t}^{*} \Lambda_{t}^{*}(x), \\
M_{t, T} \frac{\Lambda_{t}^{*}(x)}{\mathcal{E}_{t}} & =\beta^{T-t} \frac{\Lambda_{T}^{*}(x)}{\mathcal{E}_{T}}, \\
v_{l}\left(L_{t}^{*}(x), \xi_{t}^{*}\right) & =W_{t}^{*}(x) \Lambda_{t}^{*}(x),
\end{aligned}
$$

as well as a trasversality condition analogous to equation (25). Here $\mathcal{E}_{t}$ denotes the nominal exchange rate, i.e., the foreign price of home currency. Notice that the stochastic discount factor in equation (27) is the same stochastic discount factor as in equation (23). This simply reflects the fact that assets are traded on global markets in which all agents face the same prices.

From equation (22)-(23) and (26)-(27) it follows that

$$
\frac{u_{c}\left(C_{T}\right)}{u_{c}\left(C_{t}\right)}=\frac{M_{t, T}}{\beta^{T-t}} \frac{P_{T}}{P_{t}} \quad \text { and } \quad \frac{u_{c}\left(C_{T}^{*}\right)}{u_{c}\left(C_{t}^{*}\right)}=\frac{M_{t, T}}{\beta^{T-t}} \frac{\mathcal{E}_{T} P_{T}^{*}}{\mathcal{E}_{t} P_{t}^{*}} .
$$

Combining these equations yields

$$
Q_{t}=\frac{u_{c}\left(C_{t}^{*}\right)}{u_{c}\left(C_{t}\right)}
$$

where $Q_{t}=\mathcal{E}_{t} P_{t}^{*} / P_{t}$ is the real exchange rate at time $t$ and for simplicity $Q_{0}=1$.

\section{A.2 Firm Behavior}

In each country there is a continuum of firm types indexed by $z$. The home country firms have indexes on the interval $[0,1]$. The foreign country firms have indexes on the interval $(1,2]$. Firms of type $z$ specializes in the production of a differentiated good, $y_{t}(z)$. There are an equal (large) number of firms of each type.

In the following two subsections, I will describe two environments and the resulting firm behavior in each environment. I will refer to these two environments as the heterogeneous factor markets model and the homogeneous factor markets model. In both the heterogeneous factor markets model and the homogeneous factor markets model, I assume that firms are able to price discriminate between consumers in the two countries. In other words, they price-to-market (see, e.g., Krugman, 1987). Furthermore, firms denominate the price of their good in the home and foreign country in the local currency of each country. In other words, they practice local-currency pricing (see, e.g., 
Devereux, 1997). Prices are sticky in both countries. Price setting is assumed to be synchronized within each firm type but staggered between firm types. ${ }^{22}$ In each period firms of type $z$ can change their prices with probability $1-\alpha$. With probability $\alpha$ they must keep their prices unchanged. This model of price stickiness was first proposed in Calvo (1983). The fact that a firm's ability to change its prices is independent of the state of the economy makes this model simple and tractable.

\section{A.2.1 The Heterogeneous Factor Market Model}

All inputs to production except labor are fixed for each firm. Firms of type $z$ must hire labor of type $x=z$. Other types of labor are not useful in the production of goods of type $z$. In other words, the labor market is highly segmented. This may be due to the fact that specific skills are required to produce each type of good. In this case, $X$ denotes the skills each type of household is endowed with or has invested in. The production function of firms of type $z$ is

$$
y_{t}(z)=A_{t} f\left(L_{t}(z)\right)
$$

where $A_{t}$ denotes an exogenous technology factor and $L_{t}(z)$ denotes the amount of labor input used by firms of type $z$ in period $t$. The function $f$ is increasing and concave. It is concave because there are diminishing marginal returns to labor given the fixed amount of other inputs employed at the firm. Firms act to maximize their value in domestic currency.

In order to maximize profits a home country firm of type $z$ that is able to change its prices at time $t$ chooses $p_{t}(z), p_{t}^{*}(z)$ and $L_{T}(z)$ to maximize

$$
E_{t} \sum_{T=t}^{\infty} \alpha^{T-t} M_{t, T} \Phi_{T}(z)
$$

where

$$
\Phi_{T}(z)=p_{t}(z)\left(C_{H, T}+G_{H, T}\right)\left(\frac{p_{t}(z)}{P_{H, T}}\right)^{-\theta_{T}}+\mathcal{E}_{T} p_{t}^{*}(z)\left(C_{H, T}^{*}+G_{H, T}^{*}\right)\left(\frac{p_{t}^{*}(z)}{P_{H, T}^{*}}\right)^{-\theta_{T}}-W_{T}(z) L_{T}(z)
$$

subject to the constraint that it produces at least as much as it sells,

$$
\left(C_{H, T}+G_{H, T}\right)\left(\frac{p_{t}(z)}{P_{H, T}}\right)^{-\theta_{T}}+\left(C_{H, T}^{*}+G_{H, T}^{*}\right)\left(\frac{p_{t}^{*}(z)}{P_{H, T}^{*}}\right)^{-\theta_{T}} \leq A_{T} f\left(L_{T}(z)\right) .
$$

Necessary conditions for an optimal plan are

$$
E_{t} \sum_{T=t}^{\infty} \alpha^{T-t} M_{t, T}\left(C_{H, T}+G_{H, T}\right) P_{H, T}^{\theta_{T}}\left(1-\theta_{T}\right)\left[p_{t}(z)-\frac{\theta_{T}}{\theta_{T}-1} S_{T}(z)\right]=0
$$

\footnotetext{
${ }^{22}$ See Woodford (2003, section 3.1.) for an argument for why this assumption is reasonable.
} 


$$
E_{t} \sum_{T=t}^{\infty} \alpha^{T-t} M_{t, T}\left(C_{H, T}^{*}+G_{H, T}^{*}\right) P_{H, T}^{* \theta_{T}}\left(1-\theta_{T}\right)\left[\mathcal{E}_{T} p_{t}^{*}(z)-\frac{\theta_{T}}{\theta_{T}-1} S_{T}(z)\right]=0,
$$

for each period $t$ at which firms of type $z$ are able to change their prices,

$$
W_{t}(z)=A_{t} f_{l}\left(L_{t}(z)\right) S_{t}(z)
$$

for all $t$ and equation (34) with equality for all $t$. Here $S_{t}(z)$ is the marginal cost of production, i.e. the Lagrange multiplier of the firm's constrained optimization problem. Foreign firms solve an analogous optimization problem.

Combining equations (22), (24) and (37) in order to eliminate $\Lambda_{t}(z)$ and $W_{t}(z)$ gives

$$
\frac{S_{t}(z)}{P_{t}}=\frac{v_{l}\left(L_{t}(z), \xi_{t}\right)}{A_{t} f_{l}\left(L_{t}(z)\right) u_{c}\left(C_{t}\right)} .
$$

Notice that $L_{t}(z)=f^{-1}\left(y_{t}(z) / A_{t}\right)$. Using this relation, $S_{t}(z) / P_{t}$ can be written without reference to $L_{t}(z)$ as

$$
\frac{S_{t}(z)}{P_{t}}=\frac{v_{l}\left(f^{-1}\left(y_{t}(z) / A_{t}\right), \xi_{t}\right)}{A_{t} f_{l}\left(f^{-1}\left(y_{t}(z) / A_{t}\right)\right) u_{c}\left(C_{t}\right)} .
$$

Here the marginal costs of firms of type $z$ have been written in terms of their level of output and the level of domestic consumption. This is useful since it simplifies the model by eliminating both $W_{t}(z)$ and $L_{t}(z)$.

\section{A.2.2 The Homogeneous Factor Markets Model}

There exists a fixed amount of non-depretiating capital in the economy that is owned by the firms. For simplicity, I assume that firms can rent their capital stock to other firms but not sell it. All workers are identical from each firm's perspective. Firms are therefore indifferent regarding which workers they hire and all workers receive the same wage $W_{t}$ in equilibrium. The production function of firms of type $z$ is

$$
y_{t}(z)=A_{t} f\left(L_{t}(z), K_{t}(z)\right)
$$

where $A_{t}$ denotes an exogenous technology factor and $L_{t}(z)$ denotes the amount of labor input used by firms of type $z$ in period $t$ and $K_{t}(z)$ denotes the amount of capital used by firms of type $z$ in period $t$. The function $f$ is increasing in both its arguments and homogeneous of degree one. Firms act to maximize their value in domestic currency. 
In order to maximize profits a home country firms of type $z$ that are able to change its prices at time $t$ chooses $p_{t}(z), p_{t}^{*}(z), L_{T}(z)$ and $K_{t}(z)$ to maximize (32) where

$$
\begin{array}{r}
\Phi_{T}(z)=p_{t}(z)\left(C_{H, T}+G_{H, T}\right)\left(\frac{p_{t}(z)}{P_{H, T}}\right)^{-\theta_{T}}+\mathcal{E}_{T} p_{t}^{*}(z)\left(C_{H, T}^{*}+G_{H, T}^{*}\right)\left(\frac{p_{t}^{*}(z)}{P_{H, T}^{*}}\right)^{-\theta_{T}} \\
-W_{T} L_{T}(z)-R_{T}\left(K_{T}(z)-K(z)\right)
\end{array}
$$

subject to the constraint that it produces at least as much as it sells,

$$
\left(C_{H, T}+G_{H, T}\right)\left(\frac{p_{t}(z)}{P_{H, T}}\right)^{-\theta_{T}}+\left(C_{H, T}^{*}+G_{H, T}^{*}\right)\left(\frac{p_{t}^{*}(z)}{P_{H, T}^{*}}\right)^{-\theta_{T}} \leq A_{T} f\left(L_{T}(z), K_{T}(z)\right),
$$

where $R_{T}$ denotes the rental rate on capital in period $T$ and $K(z)$ denotes the capital endowment of firms of type $z$.

Necessary conditions for an optimal plan are equations (35)-(36) for each period $t$ at which firms of type $z$ are able to change their prices,

$$
\begin{aligned}
& W_{t}=A_{t} f_{l}\left(L_{t}(z), K_{t}(z)\right) S_{t}(z) \\
& R_{t}=A_{t} f_{k}\left(L_{t}(z), K_{t}(z)\right) S_{t}(z)
\end{aligned}
$$

for all $t$ and equation (42) with equality for all $t$. Notice that equations (43)-(44) imply that

$$
\frac{W_{t}}{R_{t}}=\frac{f_{l}\left(L_{t}(z), K_{t}(z)\right)}{f_{k}\left(L_{t}(z), K_{t}(z)\right)}
$$

Since $f$ is homogeneous of degree one, this implies that all firms choose the same labor-capital ratio in period $t$ even though they produce different amounts. This, in turn, implies that equation (43) can be rewritten as

$$
S_{t}=\frac{W_{t}}{A_{t} f_{l}\left(h_{t}, 1\right)}
$$

where $h_{t}$ denotes the common labor-capital ratio of all firms. Notice that this equation implies that the marginal cost of all firms is equal. I have denoted this common marginal cost as $S_{t}$.

Combining this last equations with equations (22), (24) and (43) in order to eliminate $\Lambda_{t}(z)$ and $W_{t}$ yields

$$
\frac{S_{t}}{P_{t}}=\frac{v_{l}\left(L_{t}, \xi_{t}\right)}{A_{t} f_{l}\left(h_{t}, 1\right) u_{c}\left(C_{t}\right)}
$$

where $L_{t}$ is the amount of labor supplied by the representative household. Unlike in the heterogeneous markets case, all households supply the same amount of labor when the labor market is homogeneous. 


\section{A.3 Log-Linearization of Heterogeneous Factor Markets Model}

In this section, I work out a log-linear approximation of the heterogeneous factor markets model. A log-linear approximation of the homogeneous factor markets model may be derived in an analogous fashion.

First, consider the left equation in (29). The expectation of the $T=t+1$ version of this equation may be written

$$
I_{t}=E_{t}\left[\frac{1}{\beta} \frac{u_{c}\left(C_{t}\right)}{u_{c}\left(C_{t+1}\right)} \frac{P_{t+1}}{P_{t}}\right],
$$

since the gross short term nominal interest rate is given by $I_{t}=1 / E_{t} M_{t, t+1}$. A log-linear approximation of this equations is

$$
c_{t}=E_{t} c_{t+1}-\sigma\left(i_{t}-E_{t} \pi_{t+1}\right)
$$

where $\sigma=-u_{c} / u_{c c} C$, lower case letters denote percentage deviations from steady state of the same upper case letters unless otherwise noted, uppercase letters without a time subscript denote steade state values and $\pi_{t}=\log \left(P_{t} / P_{t-1}\right)$. The foreign consumption Euler equation yields an analogous log-linear approximation.

A log-linear approximation of equation (30) is

$$
c_{t}-c_{t}^{*}=\sigma q_{t} .
$$

Log-linear approximations of the equations in (20) are

$$
\begin{aligned}
& \phi_{H} p_{H, t}+\phi_{F} p_{F, t}=0, \\
& \phi_{F} p_{H, t}^{*}+\phi_{H} p_{F, t}^{*}=0,
\end{aligned}
$$

where $p_{j, t}=\log \left(P_{j, t} / P_{t}\right)$ and I have made use of the fact that the normalization $\phi_{H}+\phi_{F}=1$ implies that all relative prices are 1 in steady state. Notice that these last two equations imply that

$$
\begin{aligned}
& \pi_{t}=\phi_{H} \pi_{H, t}+\phi_{F} \pi_{F, t} \\
& \pi_{t}^{*}=\phi_{F} \pi_{H, t}^{*}+\phi_{H} \pi_{F, t}^{*}
\end{aligned}
$$

A log-linear approximation of equation (19) is

$$
\pi_{H, t}=\frac{1-\alpha}{\alpha}\left(p_{h, t}-p_{H, t}\right)
$$




$$
\pi_{F, t}=\frac{1-\alpha}{\alpha}\left(p_{f, t}-p_{F, t}\right)
$$

where $\pi_{j, H}=\log \left(P_{j, t} / P_{j, t-1}\right)$.

Define $c_{t}^{M}$ and $c_{t}^{M *}$ as $c_{t}^{M}=\phi_{H} c_{t}+\phi_{F} c_{t}^{*}$ and $c_{t}^{M *}=\phi_{F} c_{t}+\phi_{H} c_{t}^{*}$, respectively and $M$ and $M *$ superscripts on other variables denote the analogous weighted averages. Given this notation, a log-linear approximation of (34), (39) and their foreign counterparts are

$$
\begin{gathered}
y_{t, T}=c_{T}^{M}+g_{T}^{M}+(\theta-\eta) p_{H, T}^{M}-\theta p_{h, t}^{M}+\theta \sum_{\tau=t+1}^{T} \pi_{\tau}^{M}+\phi_{H, T}^{M}, \\
y_{t, T}^{*}=c_{T}^{M *}+g_{T}^{M *}+(\theta-\eta) p_{F, T}^{M *}-\theta p_{f, t}^{M *}+\theta \sum_{\tau=t+1}^{T} \pi_{\tau}^{M *}+\phi_{F, T}^{M *}, \\
s_{t, T}=\left(\frac{v_{l l} Y}{v_{l} f_{l} A}+\frac{\Psi_{y} Y}{\Psi A}\right) y_{t, T}-\frac{u_{c c} C}{u_{c}} c_{T}+\frac{v_{l \xi}}{v_{l}} \xi_{T}-\left(\frac{v_{l l} Y}{v_{l} f_{l} A}+\frac{\Psi_{y} Y}{\Psi A}+1\right) a_{T}, \\
s_{t, T}^{*}=\left(\frac{v_{l l} Y}{v_{l} f_{l} A}+\frac{\Psi_{y} Y}{\Psi A}\right) y_{t, T}^{*}-\frac{u_{c c} C}{u_{c}} c_{T}^{*}+\frac{v_{l \xi}}{v_{l}} \xi_{T}^{*}-\left(\frac{v_{l l} Y}{v_{l} f_{l} A}+\frac{\Psi_{y} Y}{\Psi A}+1\right) a_{T}^{*} .
\end{gathered}
$$

where $s_{t, T}$ denotes the percent deviation from steady state of the real marginal cost in period $T$ of the firms that set their prices in period $t, y_{t, T}$ denotes the percent deviation from steady state in period $T$ of the level of output of firms that set their prices in period $t$ and $\Psi=1 / f_{l}\left(f^{-1}(y / A)\right)$. Also, I assume that $C=C^{*}=Y$.

Combining these last four equations to eliminate $y_{t, T}$ and $y_{t, T}^{*}$ yields

$$
\begin{gathered}
s_{t, T}=\omega\left(c_{T}^{M}+g_{T}^{M}\right)+\omega(\theta-\eta) p_{H, T}^{M}-\omega \theta p_{h, t}^{M}+\omega \theta \sum_{\tau=t+1}^{T} \pi_{\tau}^{M}+\phi_{H, T}^{M}+\sigma^{-1} c_{T}-\tilde{a}_{T}, \\
s_{t, T}^{*}=\omega\left(c_{T}^{M *}+g_{T}^{M *}\right)+\omega(\theta-\eta) p_{F, T}^{M *}-\omega \theta p_{f, t}^{M *}+\omega \theta \sum_{\tau=t+1}^{T} \pi_{\tau}^{M *}+\phi_{F, T}^{M *}+\sigma^{-1} c_{T}^{*}-\tilde{a}_{T}^{*},
\end{gathered}
$$

where

$$
\omega=\left(\frac{v_{l l} Y}{v_{l} f_{l} A}+\frac{\Psi_{y} Y}{\Psi A}\right) \quad \text { and } \quad \tilde{a}_{t}=(\omega+1) a_{t}-\frac{v_{l \xi}}{v_{l}} \xi_{t} .
$$

Log-linear approximations of equations (35) and (36) and their foreign counterparts are given by

$$
\begin{gathered}
p_{h t}=(1-\alpha \beta) \sum_{j=0}^{\infty}(\alpha \beta)^{j} E_{t}\left(s_{t, t+j}-\hat{\theta}_{t+j}\right)+\sum_{j=1}^{\infty}(\alpha \beta)^{j} E_{t} \pi_{t+j}, \\
p_{h t}^{*}=(1-\alpha \beta) \sum_{j=0}^{\infty}(\alpha \beta)^{j} E_{t}\left(s_{t, t+j}-q_{t+j}-\hat{\theta}_{t+j}\right)+\sum_{j=1}^{\infty}(\alpha \beta)^{j} E_{t} \pi_{t+j}^{*}, \\
p_{f t}^{*}=(1-\alpha \beta) \sum_{j=0}^{\infty}(\alpha \beta)^{j} E_{t}\left(s_{t, t+j}^{*}-\hat{\theta}_{t+j}^{*}\right)+\sum_{j=1}^{\infty}(\alpha \beta)^{j} E_{t} \pi_{t+j}^{*},
\end{gathered}
$$




$$
p_{f t}=(1-\alpha \beta) \sum_{j=0}^{\infty}(\alpha \beta)^{j} E_{t}\left(s_{t, t+j}^{*}+q_{t+j}-\hat{\theta}_{t+j}^{*}\right)+\sum_{j=1}^{\infty}(\alpha \beta)^{j} E_{t} \pi_{t+j},
$$

where $\hat{\theta}_{t}=\left(\theta /(\theta-1)^{2}\right) \theta_{t}$.

Combining equations (52), (54) and (56) yields

$$
\begin{aligned}
\pi_{H, t}+\frac{1-\alpha}{\alpha} p_{H, t} & =\kappa \sum_{j=0}^{\infty}(\alpha \beta)^{j} E_{t}\left(\omega\left(c_{t+j}^{M}+g_{t+j}^{M}\right)+\omega(\theta-\eta) p_{H, t+j}^{M}-\omega \theta p_{h, t}^{M}+\omega \theta \sum_{\tau=t+1}^{t+j} \pi_{\tau}^{M}\right. \\
& \left.+\sigma^{-1} c_{t+j}^{M}+\phi_{F} \sigma^{-1} c_{t+j}^{R}+\phi_{H, t+j}^{M}-\tilde{a}_{t+j}-\hat{\theta}_{t+j}\right)+\frac{1-\alpha}{\alpha} \sum_{j=1}^{\infty}(\alpha \beta)^{j} E_{t} \pi_{t+j}
\end{aligned}
$$

Notice that

$$
\sum_{j=0}^{\infty}(\alpha \beta)^{j} \sum_{\tau=t+1}^{t+j} \pi_{\tau}^{M}=\frac{1}{1-\alpha \beta} \sum_{j=1}^{\infty}(\alpha \beta)^{j} \pi_{t+j}^{M}
$$

Using this and equations (47), (52) and (60) may be written

$$
\begin{aligned}
& (1+\omega \theta)\left(\pi_{H, t}+\frac{1-\alpha}{\alpha} p_{H, t}\right)-\phi_{F} \omega \theta\left(\pi_{H, t}^{R}+\frac{1-\alpha}{\alpha} p_{H, t}^{R}\right)=\kappa \sum_{j=0}^{\infty}(\alpha \beta)^{j}\left(\omega+\sigma^{-1}\right) E_{t} c_{t+j}^{M} \\
& +\kappa \sum_{j=0}^{\infty}(\alpha \beta)^{j} E_{t}\left(\omega(\theta-\eta) p_{H, t+j}^{M}+\phi_{F}\left(q_{t+j}+\epsilon_{t+j}^{R}\right)+\phi_{H, t+j}^{M}-\tilde{a}_{t+j}+\omega g_{t+j}^{M}-\hat{\theta}_{t+j}\right) \\
& \quad+(1+\omega \theta) \frac{1-\alpha}{\alpha} \sum_{j=1}^{\infty}(\alpha \beta)^{j} E_{t} \pi_{t+j}-\phi_{F} \omega \theta \frac{1-\alpha}{\alpha} \sum_{j=1}^{\infty}(\alpha \beta)^{j} E_{t} \pi_{t+j}^{R}
\end{aligned}
$$

Now, using the fact that $p_{H, t}-p_{H, t-1}=\pi_{H, t}-\pi_{t}$ and defining

$$
\kappa=\frac{(1-\alpha)(1-\alpha \beta)}{\alpha} \text { and } \zeta=\frac{\omega+\sigma^{-1}}{1+\omega \theta}
$$

this equation can be rewritten as

$$
\begin{aligned}
\pi_{H, t}-\beta E_{t} \pi_{H, t+1}+\kappa p_{H, t}-\phi_{F} \frac{\omega \theta}{1+\omega \theta}\left(\pi_{H, t}^{R}-\beta E_{t} \pi_{H, t+1}^{R}+\kappa p_{H, t}^{R}\right) \\
=\kappa \zeta c_{t}^{M}+\kappa \frac{\omega(\theta-\eta)}{1+\omega \theta} p_{H, t}^{M}+\kappa \frac{\phi_{F}}{1+\omega \theta}\left(q_{t}+\epsilon_{t}^{R}\right)-\frac{\kappa}{1+\omega \theta}\left(\tilde{a}_{t}-\omega g_{t}^{M}-\phi_{H, t+j}^{M}+\hat{\theta}_{t}\right) .
\end{aligned}
$$

A similar set of manipulations involving $\pi_{H, t}^{*}$ yields

$$
\begin{aligned}
\pi_{H, t}^{*}-\beta E_{t} \pi_{H, t+1}^{*}+\kappa p_{H, t}^{*}+\phi_{H} \frac{\omega \theta}{1+\omega \theta}\left(\pi_{H, t}^{R}-\beta E_{t} \pi_{H, t+1}^{R}+\kappa p_{H, t}^{R}\right) \\
=\kappa \zeta c_{t}^{M}+\kappa \frac{\omega(\theta-\eta)}{1+\omega \theta} p_{H, t}^{M}-\kappa \frac{1-\phi_{F}}{1+\omega \theta}\left(q_{t}+\epsilon_{t}^{R}\right)-\frac{\kappa}{1+\omega \theta}\left(\tilde{a}_{t}-\omega g_{t}^{M}-\phi_{H, t+j}^{M}+\hat{\theta}_{t}\right) .
\end{aligned}
$$

Combining the last two equations yields

$$
\pi_{H, t}^{R}=\beta E_{t} \pi_{H, t+1}^{R}+\kappa q_{t}-\kappa p_{H, t}^{R}
$$




$$
\begin{gathered}
\pi_{H, t}^{M}=\beta E_{t} \pi_{H, t+1}^{M}+\kappa \zeta c_{t}^{M}-\kappa \frac{1+\omega \eta}{1+\omega \theta} p_{H, t}^{M}+\kappa \frac{2 \phi_{H} \phi_{F}}{1+\omega \theta} q_{t}-\frac{\kappa}{1+\omega \theta}\left(\tilde{a}_{t}-\omega g_{t}^{M}-\phi_{H, t+j}^{M}+\hat{\theta}_{t}\right), \\
\pi_{H, t}=\beta E_{t} \pi_{H, t+1}+\kappa \zeta c_{t}^{M}-\kappa \frac{1+\omega \eta}{1+\omega \theta} p_{H, t}^{M}-\kappa \phi_{F} p_{H, t}^{R}+\kappa \phi_{F} q_{t}-\frac{\kappa}{1+\omega \theta}\left(\tilde{a}_{t}-\omega g_{t}^{M}-\phi_{H, t+j}^{M}+\hat{\theta}_{t}\right), \\
\pi_{H, t}^{*}=\beta E_{t} \pi_{H, t+1}^{*}+\kappa \zeta c_{t}^{M}-\kappa \frac{1+\omega \eta}{1+\omega \theta} p_{H, t}^{M}+\kappa \phi_{H} p_{H, t}^{R}-\kappa \phi_{H} q_{t}-\frac{\kappa}{1+\omega \theta}\left(\tilde{a}_{t}-\omega g_{t}^{M}-\phi_{H, t+j}^{M}+\hat{\theta}_{t}\right) .
\end{gathered}
$$

And a similar set of manipulations involving $\pi_{F, t}$ and $\pi_{F, t}^{*}$ yields

$$
\begin{gathered}
\pi_{F, t}^{R}=\beta E_{t} \pi_{F, t+1}^{R}+\kappa q_{t}-\kappa p_{F, t}^{R}-\kappa \hat{\theta}_{t}^{R}, \\
\pi_{F, t}^{M *}=\beta E_{t} \pi_{F, t+1}^{M *}+\kappa \zeta c_{t}^{M *}-\kappa \frac{1+\omega \eta}{1+\omega \theta} p_{F, t}^{M *}-\kappa \frac{2 \phi_{F} \phi_{H}}{1+\omega \theta} q_{t}-\frac{\kappa}{1+\omega \theta}\left(\tilde{a}_{t}^{*}-\omega g_{t}^{M *}-\phi_{F, t+j}^{M *}+\hat{\theta}_{t}^{*}\right), \\
\pi_{F, t}=\beta E_{t} \pi_{F, t+1}+\kappa \zeta c_{t}^{M *}-\kappa \frac{1+\omega \eta}{1+\omega \theta} p_{F, t}^{M *}-\kappa \phi_{H} p_{F, t}^{R}+\kappa \phi_{H} q_{t}-\frac{\kappa}{1+\omega \theta}\left(\tilde{a}_{t}^{*}-\omega g_{t}^{M *}-\phi_{F, t+j}^{M *}+\hat{\theta}_{t}^{*}\right), \\
\pi_{F, t}^{*}=\beta E_{t} \pi_{F, t+1}^{*}+\kappa \zeta c_{t}^{M *}-\kappa \frac{1+\omega \eta}{1+\omega \theta} p_{F, t}^{M *}+\kappa \phi_{F} p_{F, t}^{R}-\kappa \phi_{F} q_{t}-\frac{\kappa}{1+\omega \theta}\left(\tilde{a}_{t}^{*}-\omega g_{t}^{M *}-\phi_{F, t+j}^{M *}+\hat{\theta}_{t}^{*}\right) .
\end{gathered}
$$

These equations along with equations (50) and (51) imply that

$$
\begin{aligned}
\pi_{t}=\beta E_{t} \pi_{t+1} & +\kappa \zeta\left(\phi_{H} c_{t}^{M}+\phi_{F} c_{t}^{M *}\right)-\kappa \frac{1+\omega \eta}{1+\omega \theta}\left(\phi_{H} p_{H, t}^{M}+\phi_{F} p_{F, t}^{M *}\right)-\kappa \phi_{H} \phi_{F}\left(p_{H, t}^{R}+p_{F, t}^{R}\right) \\
& +\kappa 2 \phi_{H} \phi_{F} q_{t}-\frac{\kappa}{1+\omega \theta}\left(\tilde{a}_{t}^{M}-\omega\left(\phi_{H} g_{t}^{M}+\phi_{F} g_{t}^{M *}\right)-\left(\phi_{H} \phi_{H, t}^{M}+\phi_{F} \phi_{F, t}^{M *}\right)+\theta_{t}^{M}\right) \\
\pi_{t}^{*}=\beta E_{t} \pi_{t+1}^{*} & +\kappa \zeta\left(\phi_{F} c_{t}^{M}+\phi_{H} c_{t}^{M *}\right)-\kappa \frac{1+\omega \eta}{1+\omega \theta}\left(\phi_{F} p_{H, t}^{M}+\phi_{H} p_{F, t}^{M *}\right)+\kappa \phi_{H} \phi_{F}\left(p_{H, t}^{R}+p_{F, t}^{R}\right) \\
- & \kappa 2 \phi_{H} \phi_{F} q_{t}-\frac{\kappa}{1+\omega \theta}\left(\tilde{a}_{t}^{M *}-\omega\left(\phi_{F} g_{t}^{M}+\phi_{H} g_{t}^{M *}\right)-\left(\phi_{F} \phi_{H, t}^{M}+\phi_{H} \phi_{F, t}^{M *}\right)+\theta_{t}^{M *}\right) .
\end{aligned}
$$

Using equations (48) and (49), these equations may be simplified:

$$
\begin{gathered}
\pi_{t}=\beta E_{t} \pi_{t+1}+\kappa \zeta\left(\phi_{H} c_{t}^{M}+\phi_{F} c_{t}^{M *}\right)-\kappa \frac{\left(\phi_{H}-\phi_{F}\right) \omega(\theta-\eta)}{1+\omega \theta} p_{F, t}^{M *}+\kappa 2 \phi_{H} \phi_{F} q_{t} \\
-\frac{\kappa}{1+\omega \theta}\left(\tilde{a}_{t}^{M}-\omega\left(\phi_{H} g_{t}^{M}+\phi_{F} g_{t}^{M *}\right)-\left(\phi_{H} \phi_{H, t}^{M}+\phi_{F} \phi_{F, t}^{M *}\right)+\theta_{t}^{M}\right), \\
\pi_{t}^{*}=\beta E_{t} \pi_{t+1}^{*}+\kappa \zeta\left(\phi_{F} c_{t}^{M}+\phi_{H} c_{t}^{M *}\right)+\kappa \frac{\left(\phi_{H}-\phi_{F}\right) \omega(\theta-\eta)}{1+\omega \theta} p_{F, t}^{M *}-\kappa 2 \phi_{H} \phi_{F} q_{t} \\
-\frac{\kappa}{1+\omega \theta}\left(\tilde{a}_{t}^{M *}-\omega\left(\phi_{F} g_{t}^{M}+\phi_{H} g_{t}^{M *}\right)-\left(\phi_{F} \phi_{H, t}^{M}+\phi_{H} \phi_{F, t}^{M *}\right)+\theta_{t}^{M *}\right) .
\end{gathered}
$$

Notice, furthermore, that if $\theta=\eta$ the $p_{F, t}^{M *}$ terms drop out of these equations. 


\section{B Interpretation of $\zeta$}

Woodford (2003, section 3.1) shows that in closed economy sticky price models the parameter $\zeta$ is a measure of the degree of strategic complementarity between firm pricing decisions. Here, I show that this is also true in the two country model considered in this paper. For concreteness I derive the result for the heterogeneous firms model. The argument presented below draws heavily on pages 161-162 of Woodford (2003). The agrument is more complicated in the open economy setting analyzed here due to the fact that each period four different prices are set $-p_{h, t}, p_{h, t}^{*}, p_{f, t}^{*}$, $p_{f, t}$-and the strategic complementarity between each price pair is slightly different. However, the parameter $\zeta$ turns out to be the average degree of strategic complementarity in the world economy.

In order to be able to calculate the degree of strategic complementarity between firm pricing decisions, Woodford (2003) introduces the concept of a notional short-run aggregate supply (SRAS) curve. He defines the notional SRAS curve as the relative price that maximizes a firm's current profits without reference to the past or future. In the heterogeneous factor markets model presented in appendix A, each firm actually has two such curves since each firm sets two prices in each period. The notional SRAS curves of the home firms are the first order conditions of the following constrained maximization problem:

$$
\max _{p_{t}(z), p_{t}^{*}(z)} \Phi_{t}(z)=p_{t}(z) C_{t}\left(\frac{p_{t}(z)}{P_{t}}\right)^{-\theta_{t}}+\mathcal{E}_{t} p_{t}^{*}(z) C_{t}^{*}\left(\frac{p_{t}^{*}(z)}{P_{t}^{*}}\right)^{-\theta_{t}}-W_{t}(z) L_{t}(z)
$$

subject to

$$
C_{t}\left(\frac{p_{t}(z)}{P_{t}}\right)^{-\theta_{t}}+C_{t}^{*}\left(\frac{p_{t}^{*}(z)}{P_{t}^{*}}\right)^{-\theta_{t}} \leq A_{t} f\left(L_{t}(z)\right)
$$

The following two equations are first order conditions of this problem:

$$
\frac{p_{t}(z)}{P_{t}}=\frac{\theta_{t}}{\theta_{t}-1} \frac{S_{t}(z)}{P_{t}} \quad \text { and } \quad \frac{p_{t}^{*}(z)}{P_{t}^{*}}=\frac{\theta_{t}}{\theta_{t}-1} \frac{S_{t}(z)}{P_{t}} \frac{1}{Q_{t}} .
$$

Log-linear approximations of these equations are

$$
p_{h, t}=s_{t}-\hat{\theta}_{t} \quad \text { and } \quad p_{h, t}^{*}=s_{t}-q_{t}-\hat{\theta}_{t} .
$$

Using equations (54) to eliminate $s_{t}$ yields

$$
\begin{aligned}
& p_{h, t}=\left(\omega+\sigma^{-1}\right) c_{t}^{M}+\omega(\theta-\eta) p_{H, t}^{M}-\omega \theta p_{h, t}^{M}+\phi_{F} q_{t}+\phi_{H, t}^{M}+\omega g_{t}^{M}-\tilde{a}_{t}-\hat{\theta}_{t}, \\
& p_{h, t}^{*}=\left(\omega+\sigma^{-1}\right) c_{t}^{M}+\omega(\theta-\eta) p_{H, t}^{M}-\omega \theta p_{h, t}^{M}-\phi_{H} q_{t}+\phi_{H, t}^{M}+\omega g_{t}^{M}-\tilde{a}_{t}-\hat{\theta}_{t},
\end{aligned}
$$


where I have set $\epsilon=0$ for simplicity.

An analogous derivation for the foreign firms yields

$$
\begin{aligned}
& p_{f, t}^{*}=\left(\omega+\sigma^{-1}\right) c_{t}^{M *}+\omega(\theta-\eta) p_{F, t}^{M *}-\omega \theta p_{f, t}^{M *}-\phi_{F} q_{t}+\phi_{F, t}^{M *}+\omega g_{t}^{M *}-\tilde{a}_{t}^{*}-\hat{\theta}_{t}^{*}, \\
& p_{f, t}=\left(\omega+\sigma^{-1}\right) c_{t}^{M *}+\omega(\theta-\eta) p_{F, t}^{M *}-\omega \theta p_{f, t}^{M *}+\phi_{H} q_{t}+\phi_{F, t}^{M *}+\omega g_{t}^{M *}-\tilde{a}_{t}^{*}-\hat{\theta}_{t}^{*},
\end{aligned}
$$

Taking weighted averages yields

$$
\begin{gathered}
p_{h, t}^{M}=\zeta c_{t}^{M}+\frac{\omega(\theta-\eta)}{1+\omega \theta} p_{H, t}^{M}+\frac{1}{1+\omega \theta}\left(\phi_{H, t}^{M}+\omega g_{t}^{M}-\tilde{a}_{t}-\hat{\theta}_{t}\right), \\
p_{f, t}^{M *}=\zeta c_{t}^{M *}+\frac{\omega(\theta-\eta)}{1+\omega \theta} p_{F, t}^{M *}+\frac{1}{1+\omega \theta}\left(\phi_{H, t}^{M *}+\omega g_{t}^{M *}-\tilde{a}_{t}^{*}-\hat{\theta}_{t}^{*}\right),
\end{gathered}
$$

Define nominal spending in the home and foreign countries to be $c_{t}^{n} \equiv c_{t}+\log P_{t}$ and $c_{t}^{n *} \equiv$ $c_{t}^{*}+\log P_{t}^{*}$, respectively.

Now consider a situation in which nominal spending in each country- $c_{t}^{n} \equiv c_{t}+\log P_{t}$ and $c_{t}^{n *} \equiv c_{t}^{*}+\log P_{t}^{*}$ - are fixed and the prices of all other goods in the world rise by $p$. The effects that this rise of all other prices has on the nominal notional prices $-p_{h, t}^{n M} \equiv p_{h, t}^{M}+\log P_{t}^{M}$ and $p_{f, t}^{n M *} \equiv p_{f, t}^{M *}+\log P_{t}^{M *}$-are

$$
\frac{\partial p_{h, t}^{n M}}{\partial p}=1-\zeta \text { and } \frac{\partial p_{f, t}^{n M *}}{\partial p}=1-\zeta
$$

This shows that $\zeta$ can be viewed as a measure of the demand weighted average degree of strategic complementarity for home and foreign goods. If $\zeta<1$ firm pricing decisions are strategic complements on average. If $\zeta>1$ they are strategic substitutes on average. 


\section{References}

Abuaf, N., And P. Jorion (1990): "Purchasing Power Parity in the Long Run," Journal of Finance, 45(1), 157-174.

Adler, M., and B. Lehmann (1983): "Deviations from Purchasing Power Parity in the Long Run," Journal of Finance, 38(5), 147-187.

Andrews, D. W. K., And H.-Y. Chen (1994): "Approximately Median-Unbiased Estimation of Autoregressive Models," Journal of Business and Economic Statistics, 12(2), 187-204.

Backus, D. K., and G. W. Smith (1993): "Consumption and Real Exchange Rates in Dynamic Economies with Non-Traded Goods," Journal of International Economics, 35(3-4), 297-316.

Ball, L., And D. Romer (1990): "Real Rigidities and the Non-Neutrality of Money," Review of Economic Studies, 57, 183-203.

BASU, S. (1995): "Intermediate Goods and Business Cucles: Implications for Productivity ans Welfare," American Economic Review, 85, 512-531.

Benigno, G. (2004): "Real Exchange Rate Persistence and Monetary Policy Rules," Journal of Monetary Economics, 51, 473-502.

Bergin, P. R., and R. C. Feenstra (2000): "Staggered Price Setting, Translog Preferences, and Endogenous Persistence," Journal of Monetary Economics, 45, 657-680.

(2001): "Pricing-to-Market, staggered contracts, and Real Exchange Rate Persistence," Journal of International Economics, 54, 333-359.

Blanchard, O. J., And C. Kahn (1980): "The Solution of Linear Difference Equations under Rational Expectations," Econometrica, 48, 1305-1311.

Bodenstein, M. (2005): "International Asset Markets and Real Exchange Rate Volatility," Working Paper, Northwestern University.

Bouakez, H. (2005): "Nominal Rigidity, Desired Markup Variations and Real Exchange Rate Persistence," Journal of International Economics, 61, 49-74.

Calvo, G. A. (1983): "Staggered Prices in a Utility-Maximizing Framework," Journal of Monetary Economics, 12, 383-398.

Chari, V., P. J. Kehoe, and E. R. McGrattan (2000): "Sticky Price Models of the Business Cycle: Can the Contract Multiplier Solve the Persistence Problem," Econometrica, 68(5), 11511179 .

(2002): "Can Sticky Price Models Generate Volatile and Persistent Real Exchange Rates," Review of Economic Studies, 69, 533-563.

Chen, S.-S., And C. Engel (2005): "Does 'Aggregation bias' Explain the PPP Puzzle," Pacific Economic Review, 10(1), 49-72.

Cheung, Y.-W., and K. S. Lai (2000): "On the Purchasing Powever Parity Puzzle," Journal of International Economics, 52, 321-330. 
Chol, W. W.-Y. (2005): "Real Exchange Rates, International Trade and Macroeconomic Fundamentals," Working Paper, Stanford University.

Christiano, L. J., M. Eichenbaum, and C. L. Evans (2005): "Nominal Rigidities and the Dynamic Effects of a Shock to Monetary Policy," Journal of Political Economics, 113(1), 1-45.

Corsetti, G., L. Dedola, and S. Leduc (2004): "International Risk-Sharing and the Transmission of Productivity Shocks," ECB Working Paper No. 308.

Devereux, M. B. (1997): "Real Exchange Rates and Macroeconomics: Evidence and Theory," Canadian Journal of Economics, 30, 773-808.

Eichenbaum, M., and C. L. Evans (1995): "Some Empirical Evidence on the Effects of Shocks to Monetary Policy on Exchange Rates," Quarterly Journal of Economics, 110(4), 975-1009.

Erceg, C. J., D. W. Henderson, and A. T. Levin (2000): "Optimal Monetary Policy with Staggered Wage and Price Contracts," Journal of Monetary Economics, 46, 281-313.

Farmer, R. A. E. (1999): Macroeconomic of Self-Fulfilling Prophecies. MIT Press, Cambridge, Mass.

Frankel, J. A. (1986): "International Capital Mobility and Crowding-out in the U.S. Economy: Imperfect Integration of Financial Markets or Goods Markets?," in How Open is the U.S. Economy?, ed. by R. W. Hafer, pp. 33-67, Lexington, Mass. Lexington Books.

(1990): "Zen and the Art of Modern Macroeconomics: A Commentary," in Monetary Policy for a Volatile Global Economy, ed. by W. S. Haraf, and T. D. Willett, pp. 117-123, Washington, DC. American Ecnterprise Institute for Public Policy Research.

Frankel, J. A., And A. K. Rose (1996): "A Panel Project on Purchasing Power Parity: Mean Reversion Within and Between Counties," Journal of International Economics, 40, 209-224.

Groen, J. J., and A. Matsumoto (2003): "Real Exchange Rate Persistence and Systematic Monetary Policy Behavior," Unpublished, University of Wisconsin.

Hansen, B. E. (1999): "The Grid Bootstrap and the Autoregressive Model," Review of Economics and Statistics, 81(4), 594-607.

Huizinga, J. (1987): "An Empirical Investigation of the Long-Run Behavior of Real Exchange Rates," Carnegie-Rochester Conference Series on Public Policy, 27, 149-214.

Imbs, J., H. Mumtaz, M. O. Ravn, and H. Rey (2005): "PPP Strikes Back: Aggregation and the Real Exchange Rate," Quarterly Journal of Economics, 120(1), 1-43.

Jeanne, O. (1998): "Generating Real Persistent Effects of Monetary Shocks: How Much Nominal Rigidity Do we Really Need?," European Economic Review, 32, 1009-1032.

Kimball, M. S. (1995): "The Quantitative Analytics of the Basic Noemonetarist Model," Journal of Money, Credit and Banking, 27, 1241-1277.

Krugman, P. R. (1987): "Pricing to Market When the Exchange Rate Changes," in Real-Financial Linkages Among Open Economies, ed. by S. W. Arndt, and J. D. Richardson, pp. 49-70, Cambridge, Mass. MIT Press. 
Meese, R., And K. Rogoff (1988): "What is Real? The Exchange Rate-Interest Rate Differential Relation over the Modern Floating-Rate Period," Journal of Finance, 43(4), 933-948.

Michael, P., A. R. Nobay, and D. A. Peel (1997): "Transactions Costs and Nonlinear Adjustment in Real Exchange Rates: An Empirical Investigation," Journal of Political Economics, $105(4), 862-879$.

Murray, C. J., and D. H. Papell (2002): "The Purchasing Power Parity Persistence Paradigm," Journal of International Economics, 65, 1-19.

Neiss, K. S., And E. PAPpa (2005): "Persistence without too much stickiness: The Role of Variable Factor Utilization," Review of Economic Dynamics, 8, 231-255.

Obstfeld, M., And K. Rogoff (1995): "Exchange Rate Dynamics Redux," Journal of Political Economics, 103(3), 624-660.

Reidel, D., And J. Szilagyi (2005): "A Biased View of PPP,” Working Paper, Harvard University.

Rogoff, K. (1996): "The Purchasing Power Parity Puzzle," Journal of Economic Literature, 34, 647-668.

Roll, R. (1979): "Violations of Purchasing Power Parity and Their Implications for Efficient International Commodity Markets," in International Finance and Trade, ed. by M. Sarnat, and G. P. Szego, pp. 133-176. Ballinger, Cambridge, Mass.

Sims, C. A. (2001): "Solving Linear Rational Expectations Model," Journal of Computational Economics, 20, 1-20.

SondergaArd, J. (2004): "Variable Capital Utilization, Staggered Wages and Real Exchange Rate Persistence," Working Paper, Georgetown University.

TAYlor, A. M. (2001): "Potential Pitfalls for the Purchasing-Power Parity Puzzle? Sampling and Specification Biases in Mean-Reversion Tests of the Law of One Price," Econometrica, 69, 473-498.

TAYlor, J. B. (1980): "Aggregate Dynamics and Staggered Contracts," Journal of Political Economics, 88, 1-23.

(1999): "Staggered Price and Wage Setting in Macroeconomics," in Handbook of Macroeconomics, ed. by J. B. Taylor, and M. Woodford, pp. 1009-1050, Amsterdam, Holland. Elsevier.

Taylor, M. P., D. A. Peel, and L. Sarno (2001): "Nonnlinear Mean-Reversion in Real Exchange Rates: Towards a Solution to the Purchasing Power Parity Puzzle," International Economic Review, 42, 1015-1042.

Woodford, M. (2003): Interest and Prices. Princton University Press, New Jersey. 
Table 1: Empirical Properties of the Trade Weighted U.S. Real Exchange Rate

Panel A: Point and Interval Estimation

\begin{tabular}{lcc}
\hline Statistic & MU point estimate & $95 \%$ Confidence Interval \\
\hline$\alpha$ & 0.953 & {$[0.879,1.000]$} \\
Half-life & 4.33 & {$[2.14, \infty]$} \\
Up-life & 3.06 & {$[0.67, \infty]$} \\
Quarter-life & 5.42 & {$[2.83, \infty]$} \\
UL/HL & 0.71 & {$[0.24,0.86]$} \\
QL - HL & 1.09 & {$[0.51,14.44]$} \\
2 HL - QL & 3.24 & {$[-0.66,9.45]$} \\
$\rho_{1, h p}$ & 0.82 & {$[0.69,0.91]$} \\
St.Dev $(\mathrm{Q}) / \operatorname{St} . \operatorname{Dev}(\mathrm{C})$ & 3.72 & \\
\hline
\end{tabular}

Panel B: Hypothesis Testing

\begin{tabular}{lc}
\hline Hypothesis & P-value \\
\hline$\alpha=1$ & 0.055 \\
$\mathrm{UL} / \mathrm{HL}=0$ & 0.006 \\
$2 \mathrm{HL}-\mathrm{QL}<0$ & 0.085 \\
\hline
\end{tabular}

UL, HL and QL refer to the up-life, half-life and quarter-life of the real exchange rate, respectively. The statistic $\rho_{1, h p}$ denotes the first order autocorrelation of the HP-filtered real exchange rate. Point estimates of the parameters $\alpha$ and $\psi$ in equation (1) were calculated using the grid-bootstrap method described in Hansen (1999) with parameters $\mathrm{G}=50, \mathrm{~B}=199$. Point estimates for other statistics were calculated from the estimates for $(\alpha, \psi)$. The lag length was chosen to be $p=5$ (see the text for a discusion of this choice). Confidence intervals and P-values were calculated using a conventional bootstrap with sample size 1000. Confidence intervals for UL/HL, QL - HL and 2HL - QL are calculated conditional on these statistics being defined. 
Table 2: Empirical Properties of Bilateral Real Exchang Rates

Panel A: UL/HL

\begin{tabular}{lccccc}
\hline & Canada & Germany & Japan & Switzl. & U.K. \\
\hline Germany & 0.50 & & & & \\
Japan & 0.44 & 0.25 & & & \\
Switzerland & 0.42 & 0.00 & 0.38 & & \\
U.K. & 0.23 & 0.26 & 0.50 & 0.26 & \\
U.S. & - & 0.49 & 0.51 & 0.53 & 0.28 \\
\hline
\end{tabular}

Panel B: HL and QL - HL

\begin{tabular}{lccccc}
\hline HL / QL-HL & Canada & Germany & Japan & Switz. & U.K. \\
\hline Germany & 2.57 & & & & \\
& 1.04 & & & & \\
Japan & 9.37 & 6.63 & & & \\
& 5.61 & 5.26 & & & \\
Switzerland & 3.21 & 2.20 & 2.38 & & \\
& 1.64 & 2.44 & 1.48 & & \\
U.K. & 8.56 & 5.19 & 3.70 & 2.00 & \\
& 6.92 & 4.07 & 2.15 & 0.96 & \\
U.S. & $\infty$ & 3.25 & 4.70 & 2.48 & 2.23 \\
& $\infty$ & 1.21 & 2.27 & 0.94 & 1.00 \\
\hline
\end{tabular}

The table reports median unbiased point estimates. UL, HL and QL refer to the up-life, half-life and quarter-life of the real exchange rate, respectively. Point estimates of the parameters $\alpha$ and $\psi$ in equation (1) were calculated using the grid-bootstrap method described in Hansen (1999) with parameters $\mathrm{G}=50$ and $\mathrm{B}=199$. Point estimates for other statistics were calculated from the estimates for $(\alpha, \psi)$. The lag length was chosen to be $p=5$ (see the text for a discusion of this choice). 
Table 3: Empirical Properties of Bilateral Real Exchang Rates

\begin{tabular}{lccccc} 
Panel $A: \mathrm{H}_{0}: \mathrm{UL} / \mathrm{HL}=0$ & & & \\
\hline & Canada & Germany & Japan & Switzl. & U.K. \\
\hline Germany & 0.30 & & & & \\
Japan & 0.15 & 0.06 & & & \\
Switzerland & 0.40 & 0.89 & 0.28 & & \\
U.K. & 0.03 & 0.29 & 0.00 & 0.43 & \\
U.S. & 0.23 & 0.21 & 0.07 & 0.43 & 0.08 \\
\hline
\end{tabular}

Panel $A: \mathrm{H}_{0}: \mathrm{HL}=\mathrm{QL}-\mathrm{HL}$

\begin{tabular}{lccccc}
\hline & Canada & Germany & Japan & Switzl. & U.K. \\
\hline Germany & 0.08 & & & & \\
Japan & 0.06 & 0.17 & & & \\
Switzerland & 0.10 & 0.58 & 0.16 & & \\
U.K. & 0.16 & 0.17 & 0.05 & 0.12 & \\
U.S. & 0.10 & 0.06 & 0.05 & 0.07 & 0.09 \\
\hline
\end{tabular}

Panel C: $\mathrm{H}_{0}: \alpha=1$

\begin{tabular}{lccccc}
\hline HL / QL-HL & Canada & Germany & Japan & Switzl. & U.K. \\
\hline Germany & 0.02 & & & & \\
Japan & 0.24 & 0.27 & & & \\
Switzerland & 0.05 & 0.10 & 0.03 & & \\
U.K. & 0.33 & 0.17 & 0.08 & 0.00 & \\
U.S. & 0.47 & 0.04 & 0.11 & 0.01 & 0.03 \\
\hline
\end{tabular}

The table reports P-values for the hypothesis tests in question. UL, HL and QL refer to the up-life, half-life and quarter-life of the real exchange rate, respectively. Point estimates of the parameters $\alpha$ and $\psi$ in equation (1) were calculated using the grid-bootstrap method described in Hansen (1999) with parameters $\mathrm{G}=50$ and $\mathrm{B}=199$. Point estimates for other statistics were calculated from the estimates for $(\alpha, \psi)$. The lag length was chosen to be $p=5$ (see the text for a discusion of this choice). P-values were calculated using a conventional bootstrap with sample size 1000 . P-values for UL/HL, QL - HL and 2HL - QL are calculated conditional on these statistics being defined. 
Table 4: Behavior the Real Exchange Rate in the Model

\begin{tabular}{llccccc}
\hline \hline & & $\mathrm{HL}$ & $\mathrm{UL} / \mathrm{HL}$ & $\mathrm{QL}-\mathrm{HL}$ & $\rho_{1, h p}$ & $\frac{\operatorname{st.dev}\left(q_{t}\right)}{\operatorname{st.dev}\left(c_{t}\right)}$ \\
\hline 1. & Trade Weighted U.S. & 4.33 & 0.71 & 1.09 & 0.82 & 3.7 \\
& Real Exchange Rate & {$[2.14, \infty]$} & {$[0.24,0.86]$} & {$[0.51,14.41]$} & {$[0.69,0.91]$} & \\
2. & Homog. Factor Markets & 0.58 & 0.00 & 0.60 & 0.54 & 5.1 \\
& Money Supply Shocks & {$[0.46,1.06]$} & {$[0.00,0.00]$} & {$[0.42,1.27]$} & {$[0.39,0.67]$} & {$[4.1,6.5]$} \\
3. & Heterog. Factor Markets & 1.12 & 0.00 & 1.04 & 0.65 & 3.6 \\
& Money Supply Shocks & {$[0.73,3.70]$} & {$[0.00,0.49]$} & {$[0.63,3.85]$} & {$[0.49,0.78]$} & {$[2.6,5.0]$} \\
4. & Extreme Model & 1.41 & 0.00 & 1.42 & 0.65 & 1.4 \\
Money Supply Shocks & {$[0.92, \infty]$} & {$[0.00,0.36]$} & {$[0.81,8.02]$} & {$[0.50,0.77]$} & {$[1.0,2.0]$} \\
5. & Heterog. Factor Markets & 3.81 & 0.36 & 2.55 & 0.84 & 3.8 \\
& Phillips Curve Shocks & {$[1.39, \infty]$} & {$[0.00,0.62]$} & {$[0.77,16.98]$} & {$[0.73,0.90]$} & {$[2.4,5.8]$} \\
\hline
\end{tabular}

The table reports median unbiased estimates and $95 \%$ confidence intervals. HL denotes halflife (measured in years), UL/HL denotes up-life divided by half-life, $\rho_{1, h p}$ denotes the first order autocorrelation of the HP-filtered series and $\operatorname{st} \cdot \operatorname{dev}\left(q_{t}\right) / \operatorname{st} \cdot \operatorname{dev}\left(c_{t}\right)$ denotes the standard deviation of HP-filtered $q_{t}$ divided by the standard deviation of HP-filtered $c_{t}$. Point estimates of HL, UL/HL and QL - HL were calculated by estimating equation (1) with $p=5$ using the grid-bootstrap method described in Hansen (1999) with parameters $\mathrm{G}=50$ and $\mathrm{B}=199$. Confidence intervales for HL, UL/HL, QL - HL were calculated using a conventional bootstrap with sample size 500. The point estimates and confidence intervales for $\rho_{1, h p}$ and $\operatorname{st} \cdot \operatorname{dev}\left(q_{t}\right) / \operatorname{st} \cdot \operatorname{dev}\left(c_{t}\right)$ were calculated by simulating 500 data series from each model - each of lenght 120 (corresponding to the length of my data set). The point estimate is the median value and the end points of the confidence intervals are the $2.5 \%$ and $97.5 \%$ quantiles of the resulting distribution. 
Table 5: Parameter Values

Benchmark Calibration:

Discount factor

Coef. of relative risk avertion

Marginal cost elasticity

Elasticity of demand

Fraction of firms that change prices

Home bias parameters

Money demand parameters

Money growth parameters

Phillips curve shocks

Composite parameters:

$$
\begin{aligned}
& \kappa=\frac{(1-\alpha)(1-\alpha \beta)}{\alpha}=0.086 \\
& \zeta_{\text {homog. }}=\omega+\sigma^{-1}=8
\end{aligned}
$$

$$
\begin{aligned}
& \beta=0.99 \\
& \sigma^{-1}=5 \\
& \omega=3 \\
& \theta=10 \\
& 1-\alpha=0.25 \\
& \phi_{H}=0.942, \phi_{F}=0.058 \\
& \psi_{i}=9.36, \psi_{c}=1 \\
& \rho_{m}=0.68, \operatorname{corr}\left(\nu_{t}, \nu_{t}^{*}\right)=0.5 \\
& \rho_{\eta}=0.85, \operatorname{corr}\left(\nu_{a, t}, \nu_{a, t}^{*}\right)=0
\end{aligned}
$$

$\gamma_{q}=2 \phi_{H} \phi_{F}=0.109$

$\zeta_{\text {heterog. }}=\frac{\omega+\sigma^{-1}}{1+\omega \theta}=0.26$ 
Figure 1: U.S. Real Exchange Rate

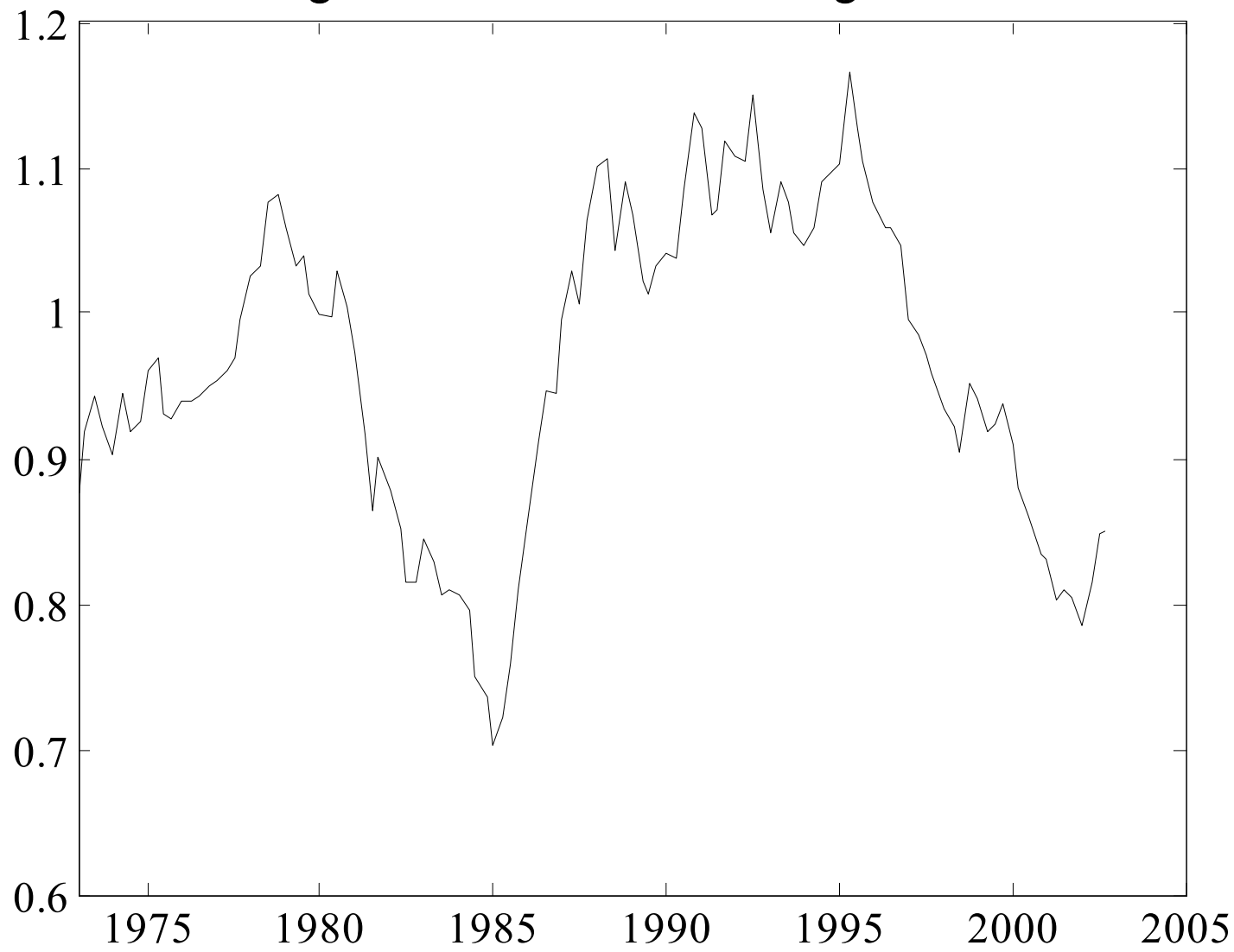

Note: This real exchange rate series is published by the Federal Reserve Board. It is the trade weighted real exchange rate of the U.S against "major" currencies. I have rescaled the series so that is equal to 1 in 1980:1. This is the level of the real exchange rate, not its $\log$. 
Figure 2: Impulse Response of the U.S. Real Exchange Rate

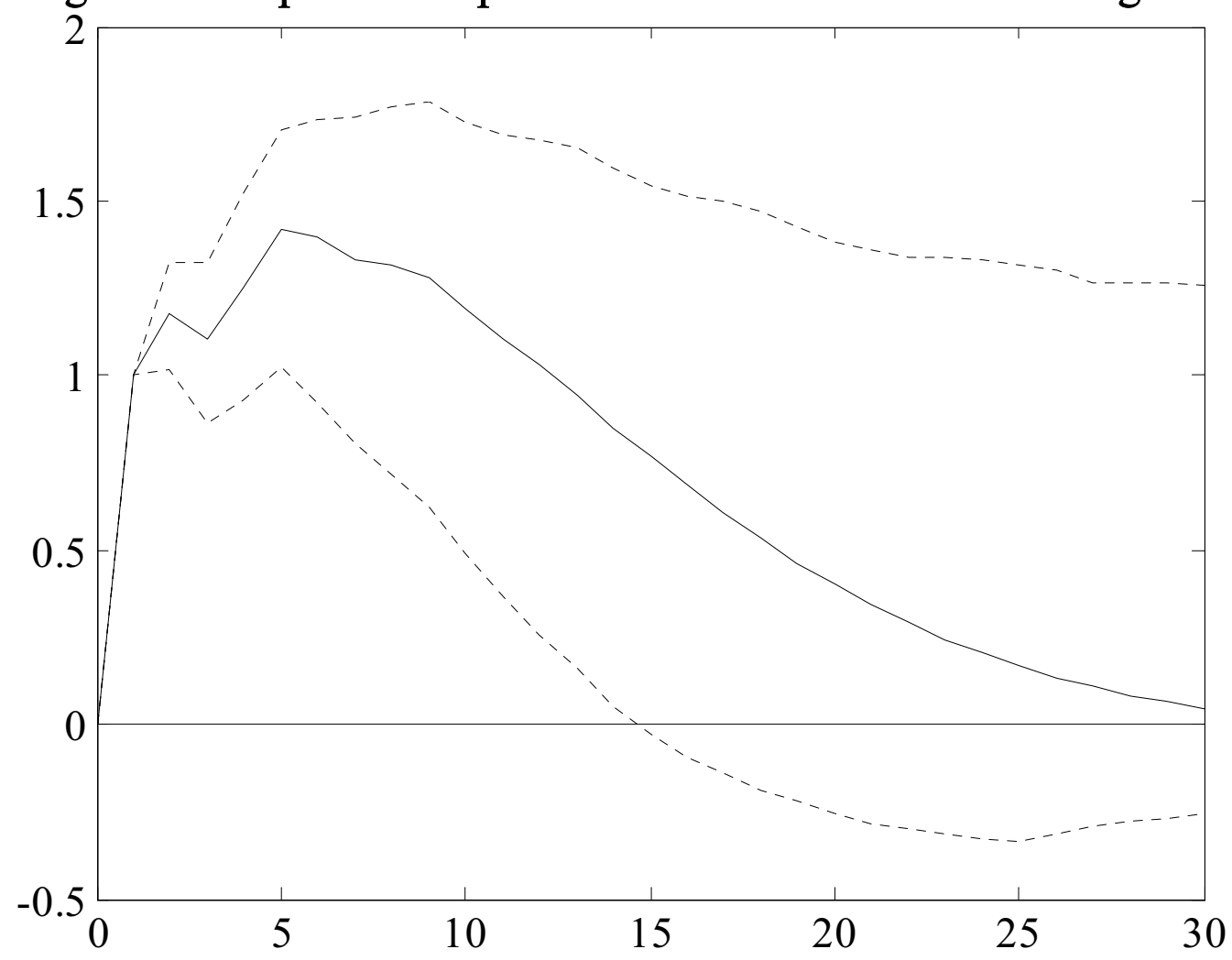

Note: Estimated impulse response for the U.S real exchange rate implied by median unbiased estimation of equation (1). Dotted lines denote $90 \%$ confidence bands. 
Figure 3: Response of the Real Exchange Rate to a Monetary Shock

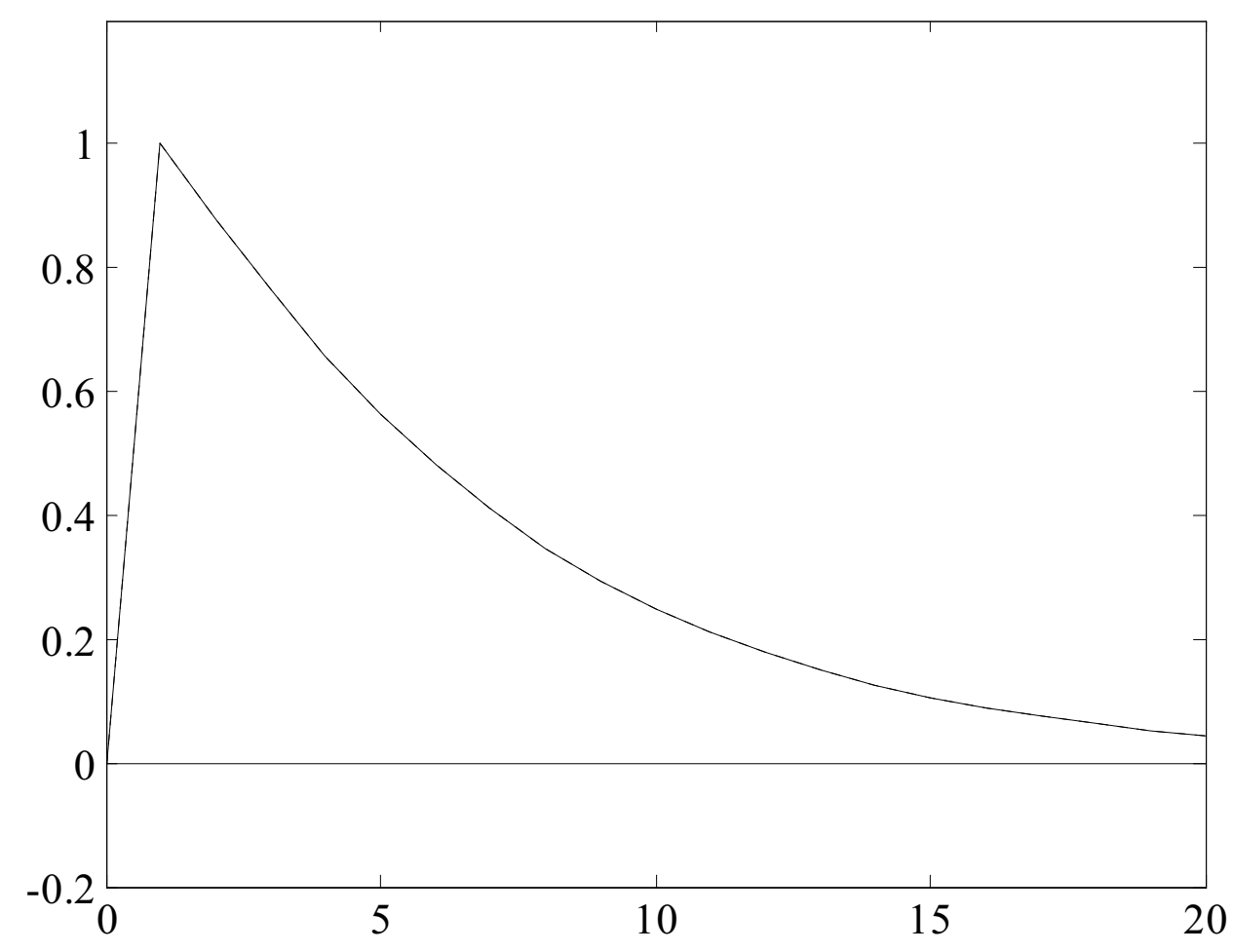

Note: The response of the real exchange rate to a shock to the home money supply in the model with heterogeneous labor markets $(\zeta=0.26)$. 
Figure 4: Response of the Real Exchange Rate to a Phillips curve shock

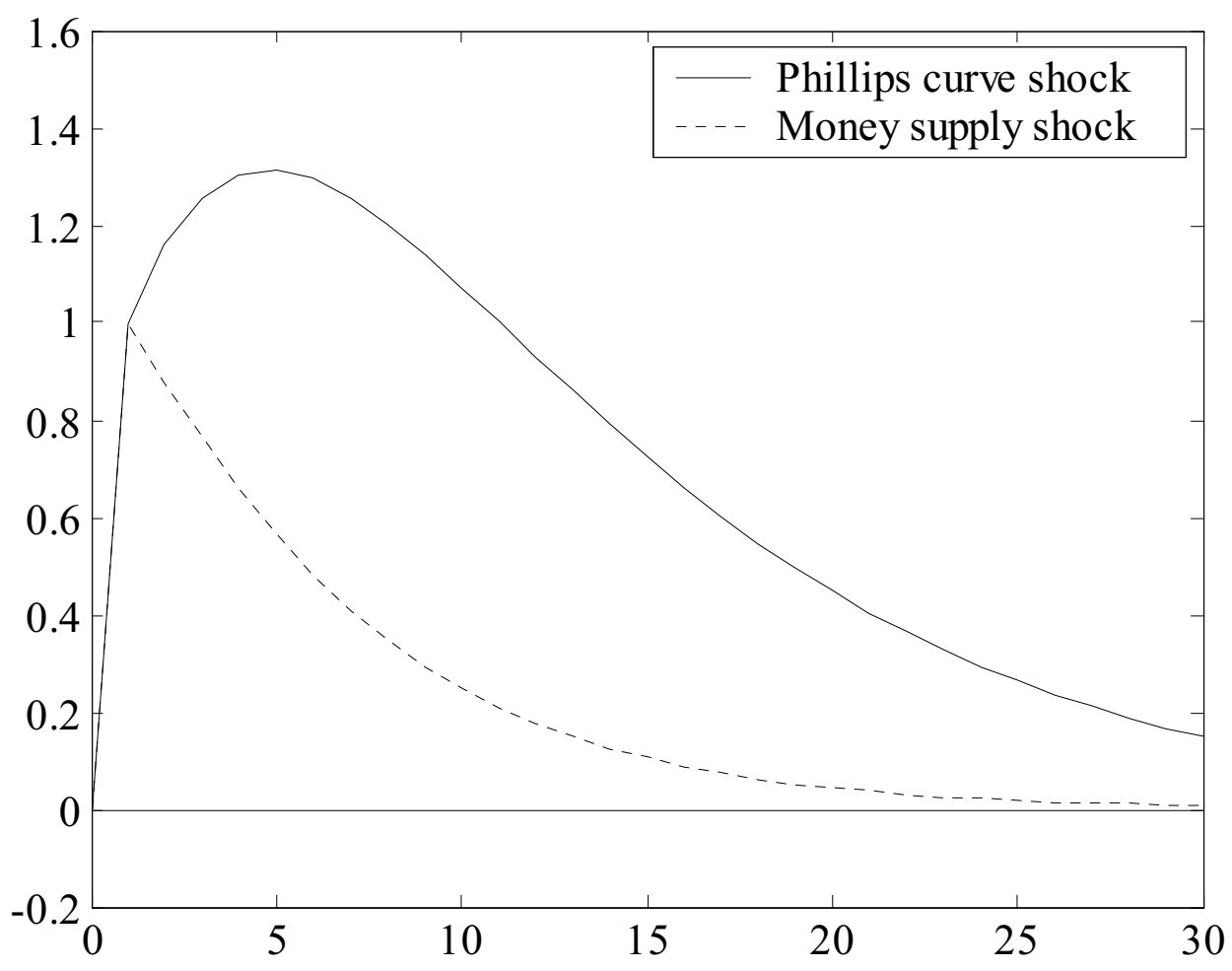

Note: The response of the real exchange rate to a shock to the home Phillips curve in the model with heterogeneous labor markets $(\zeta=0.26)$. Also reported is the response of the real exchange rate to a shock in the home money supply (dotted line). 
Figure 5: Desired Path of the Real Interest Rate

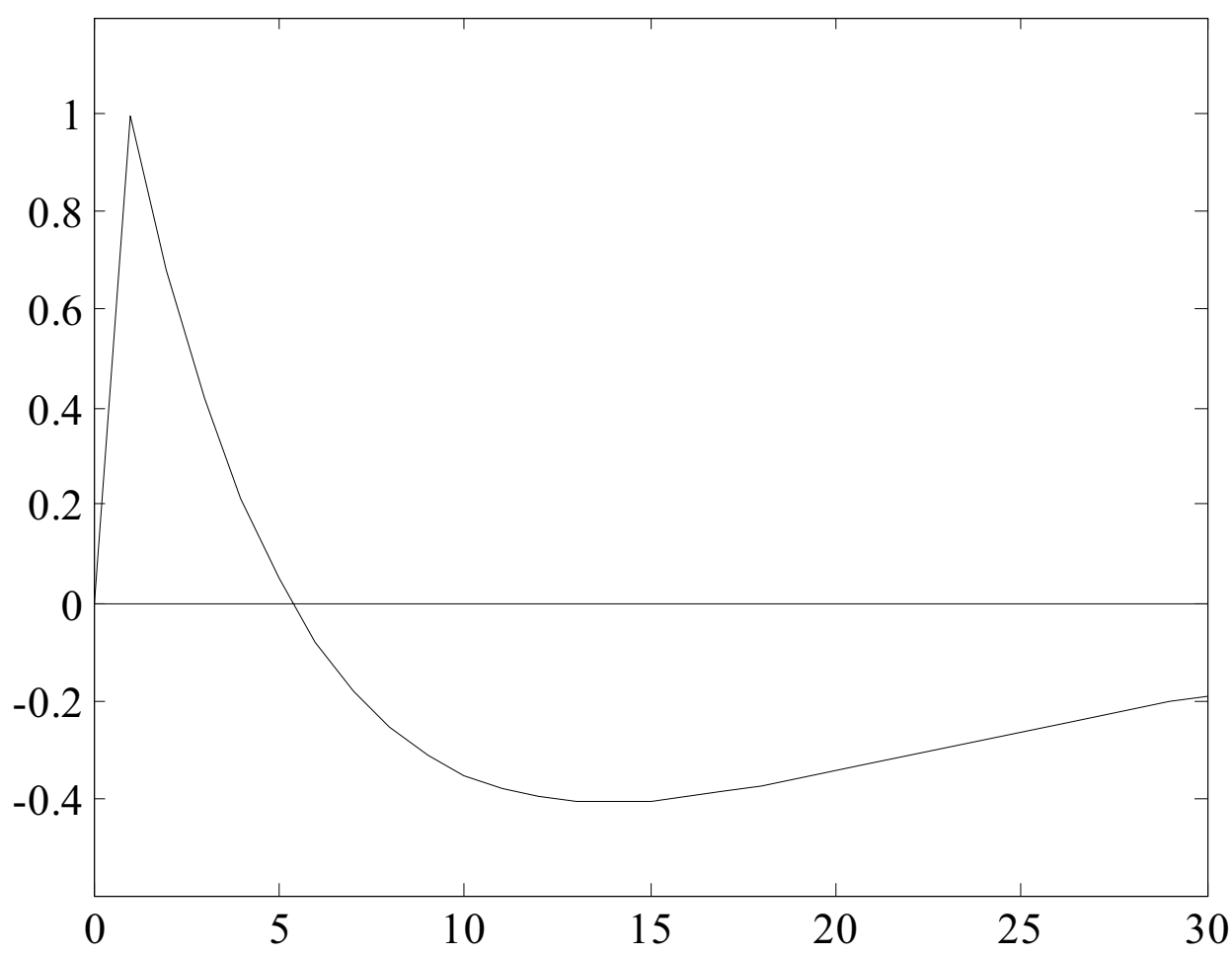


Figure 6: Response of Consumption and Inflation to a Money Supply Shock

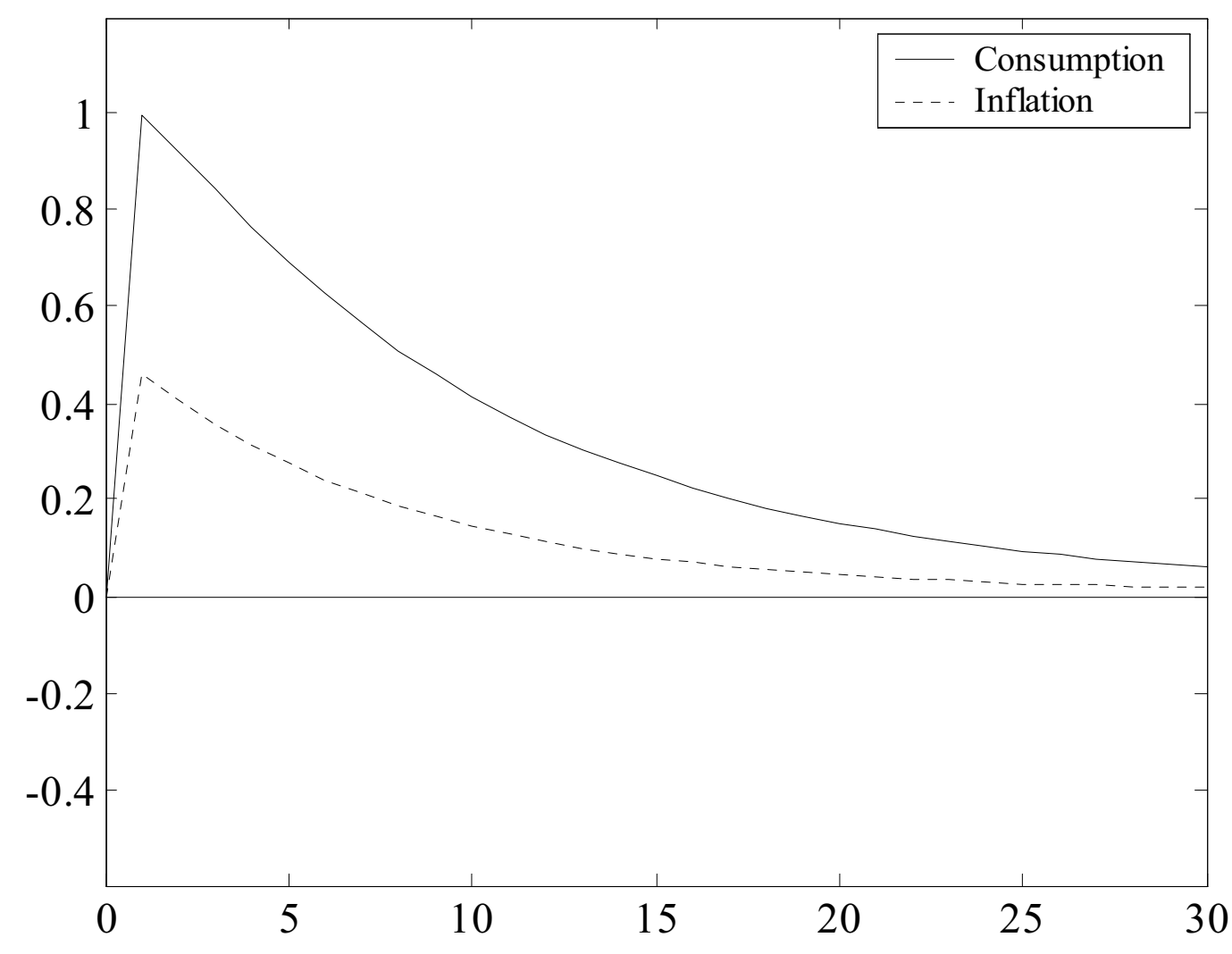


Figure 7: Response of Consumption and Inflation to a Phillips Curve Shock

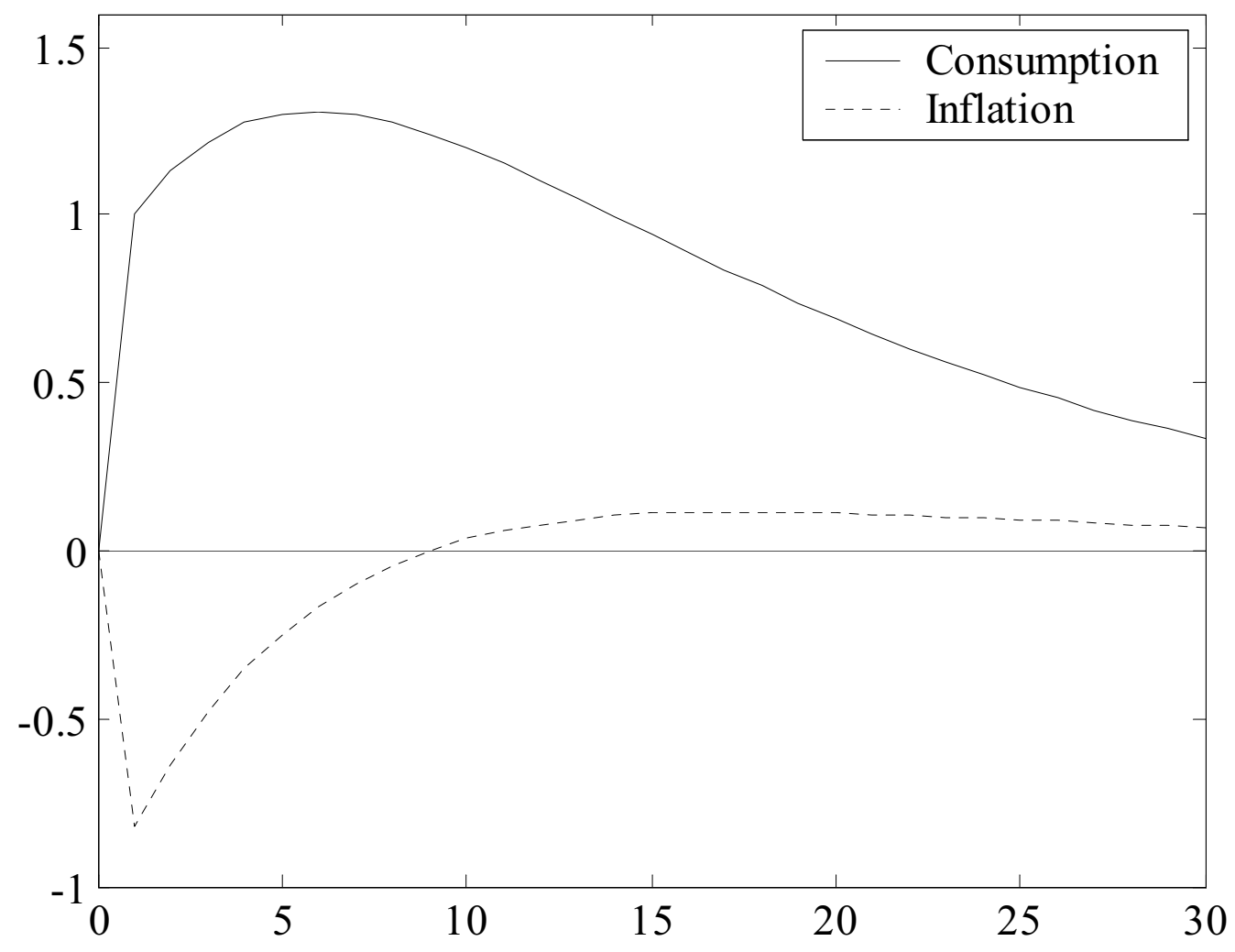

